\title{
Feasibility of retrieving dust properties and total column water vapor from solar spectra measured using a lander camera on Mars
}

Naohiro Manago ${ }^{1 *}$ (D, Katsuyuki Noguchi ${ }^{2}$, George L. Hashimoto ${ }^{3}$, Hiroki Senshu ${ }^{4}$, Naohito Otobe ${ }^{5}$, Makoto Suzuki ${ }^{6}$ and Hiroaki Kuze ${ }^{1}$

\begin{abstract}
Dust and water vapor are important constituents in the Martian atmosphere, exerting significant influence on the heat balance of the atmosphere and surface. We have developed a method to retrieve optical and physical properties of Martian dust from spectral intensities of direct and scattered solar radiation to be measured using a multi-wavelength environmental camera onboard a Mars lander. Martian dust is assumed to be composed of silicate-like substrate and hematite-like inclusion, having spheroidal shape with a monomodal gamma size distribution. Error analysis based on simulated data reveals that appropriate combinations of three bands centered at 450, 550, and $675 \mathrm{~nm}$ wavelengths and 4 scattering angles of $3^{\circ}, 10^{\circ}, 50^{\circ}$, and $120^{\circ}$ lead to good retrieval of four dust parameters, namely, aerosol optical depth, effective radius and variance of size distribution, and volume mixing ratio of hematite. Retrieval error increases when some of the observational parameters such as color ratio or aureole are omitted from the retrieval. Also, the capability of retrieving total column water vapor is examined through observations of direct and scattered solar radiation intensities at 925, 935, and $972 \mathrm{~nm}$. The simulation and error analysis presented here will be useful for designing an environmental camera that can elucidate the dust and water vapor properties in a future Mars lander mission.
\end{abstract}

Keywords: Mars atmosphere, Dust particles, Total column water vapor, Direct solar radiation, Scattered solar radiation, Radiative transfer simulation, Inverse analysis

\section{Introduction}

Dust floating in the Martian atmosphere plays an important role in determining the circulation of atmosphere, since dust is an important heat source in the atmosphere due to the absorption of solar radiation (Gierasch and Goody 1972; Moriyama 1975; Smith 2008). Accurate knowledge of the temporal and spatial distribution of dust particles, as well as their optical parameters, is indispensable for understanding their impact on the heat balance of the planet. Also, it is known that a trace amount of water vapor exists in the Martian atmosphere (Fedorova et al. 2009; Smith 2009; Smith, et

\footnotetext{
*Correspondence: manago.naohiro@chiba-u.jp

${ }^{1}$ Center for Environmental Remote Sensing, Chiba University, 1-33 Yayoi-cho,

Inage-ku, Chiba-shi, Chiba 263-8522, Japan

Full list of author information is available at the end of the article
}

al. 2009; Whiteway et al. 2009). The condensation of water vapor leads to the formation of water ice clouds, which can also affect the heat balance of the Martian atmosphere (Flasar and Goody 1976; Haberle et al. 2001; Hinson and Wilson 2004).

Observations of air-borne dust and water vapor in the Martian atmosphere have been performed by Mars orbiters and landers as well as ground-based observations (Smith 2008). As compared with orbiter observations, lander measurements are less likely to be influenced by changes in surface albedo. The dust source is on the surface of Mars, and the concentration of dust is highest near the surface. Thus, compared with orbiters, more accurate measurement can be done from landers. Also, local parameters such as pressure and temperature can be measured precisely from landers. Among the various 
observational methods used so far, the measurements of direct solar radiation (DSR) and scattered solar radiation (SSR) with cameras onboard Mars landers have brought a wealth of information on dust properties. The optical depth of dust can be retrieved as a function of wavelength from DSR measurement, while other optical properties and information on the composition of dust particles can be extracted by coupled analysis of DSR and SSR intensities.

The first observation of dust in the Martian atmosphere was made with the Imaging Camera (Patterson et al. 1977) onboard the Viking Lander (Pollack et al. 1977, 1979, 1995). The optical depth of dust was measured with the Imager for Mars Pathfinder (IMP) experiment (Smith et al. 1997), which revealed seasonal variation similar to the result of the Viking observation, with limited inter-annual variations (Smith and Lemmon 1999; Tomasko et al. 1999; Markiewicz et al. 1999). Subsequently, similar observations were made with Panchromatic Cameras (Pancam, onboard the Spirit and Opportunity rovers) (Bell et al. 2003; Bell et al. 2004a, 2004b; Lemmon et al. 2004), a Surface Stereo Imager (SSI) (onboard the Phoenix) (Lemmon et al. 2008; Moores et al. 2010), and Mastcam (onboard Curiosity) (Malin et al. 2010; Moore et al. 2016). The first observation of water vapor in the Martian atmosphere was carried out with the IMP (Titov et al. 1999), in which 6 spectral bands around $940 \mathrm{~nm}$ were employed.

The effective radius $\left(r_{\text {eff }}\right)$ and its variance $\left(v_{\text {eff }}\right)$ are the most important parameters that determine dust's optical behavior. As reviewed by Tomasko et al. (1999), the most plausible values for $r_{\text {eff }}$ and $v_{\text {eff }}$ from early observations are in a range of $1.2-1.8 \mu \mathrm{m}$ and $0.2-1.0$, respectively. In subsequent missions such as Spirit and Opportunity, the value of $r_{\text {eff }}$ was estimated to be $\sim 1.5 \mu \mathrm{m}$ (with the value of $v_{\text {eff }}$ fixed at 0.2 ). The lidar observation of Phoenix reported values between 1.2 and $1.4 \mu \mathrm{m}$ (Komguem et al. 2013). The variation in the $r_{\text {eff }}$ estimated by several missions may indicate that there are temporal and spatial variations of dust properties. Thus, it is desirable to carry out long-term observations at various locations on the Mars surface to monitor changes in dust properties.

The most dominant composition of Martian dust is considered to be basalt, and its weathering products due presumably to past volcanic activity (Dabrowska et al. 2015). The reflectance spectrum in the wavelength range of $0.3-2.5 \mu \mathrm{m}$ suggests that the rock type is most likely palagonites, the partially recrystallized products of basalt-glass influenced by wind erosion (Dlugach et al. 2003). The value of the real part of the refractive index (RI) is $\sim 1.5$ at a wavelength of $0.5 \mu \mathrm{m}$, which is close to the value of silicate. The imaginary part, on the other hand, is negligibly small in visible and near-infrared wavelengths, but its value substantially increases toward the shorter wavelengths, suggesting the contribution of iron oxide components (Dlugach et al. 2003). Thus, it is possible that dust particles contain small amounts of crystalline ferric materials such as goethite, hematite, and/or maghemite.

In this paper, we examine the feasibility of retrieving dust properties and total column water vapor (TCWV) in the Martian atmosphere with a camera system onboard a lander. Such camera observation can be realized by modifying a lander camera system with the addition of optical filters. We develop a dust model in which dust properties are parameterized with a small number of "dust model parameters", including optical depth, effective radius/variance of dust size distribution, volume mixing ratio of hematite, complex RI of silicate, and scale height of dust. Since Martian dust's properties are simpler than those of terrestrial aerosols, we can safely assume a simple dust model. A relatively small number (seven) of dust model parameters are used in this model, which helps to alleviate the underconstrained (ill-posed) nature of the inverse problem. These parameter values are optimized by fitting a small number of "observational parameters" based on DSR and SSR measurements. Only three wavelength bands are utilized for dust observations, which helps keep camera hardware size and data transmission requirements small. Another set of two or three wavelengths around $935 \mathrm{~nm}$ is postulated for extracting TCWV from DSR/SSR measurements. We also examine the feasibility of such a camera measurement on the basis of sensor specifications currently available.

\section{Methods/Experimental}

Dust model based on non-spherical shape and monomodal size distribution

First, we describe the model used to parameterize the optical and physical properties of Martian dust. Basically, the present model is relevant to the physical conditions of dust particles including their composition, shape, and spatial distribution in the Martian atmosphere. The dust composition can be parameterized with a complex RI that depends on substance and wavelength, $\lambda$. From past studies (e.g., Hamilton and Christensen 2005 and references therein), it is plausible that Martian dust is mostly composed of silicates, with small amounts of iron oxides such as hematite. Thus, in the present analysis, we assume a two-component dust model with silicate substrate and hematite inclusion. Similar treatment of a multi-component aerosol was employed in the analysis of the terrestrial atmosphere (Manago and Kuze 2010; Manago et al. 2011). The complex RI value of silicate ( $n_{0}=m_{0}-k_{0} i, i$ : imaginary unit) can be characterized with $m_{0} \sim 1.5$ and $k_{0} \ll 1$, representing small absorption of 
visible light (e.g., Table 1 in Dabrowska et al. 2015, Table 5 in Levoni et al. 1997), while that of hematite is parameterized as $n_{A}(\lambda)=m(\lambda)-k(\lambda) i$, in which we should consider the large absorbance of blue light. Referring to Querry (1985) for the wavelength dependence of $m(\lambda)$ and $k(\lambda)$, the RI of their mixture, $n$, can be calculated using Maxwell-Garnett theory (Ehlers et al. 2014) as

$$
n^{2}=n_{0}^{2} \frac{n_{A}^{2}+2 n_{0}^{2}+2 \rho_{A}\left(n_{A}^{2}-n_{0}^{2}\right)}{n_{A}^{2}+2 n_{0}^{2}-\rho_{A}\left(n_{A}^{2}-n_{0}^{2}\right)}
$$

Here, $\rho_{A}$ is the volume mixing ratio of hematite. Figure 1 shows the wavelength dependence of dust RI reported in Wolff et al. (2009). Figure 1 also shows an example of the fitting we did using Eq. (1), resulting in $n_{0}=1.48-0.000942 i\left(m_{0}=1.48\right.$ and $\left.k_{0}=0.000942\right)$ for the complex RI of silicate and $\rho_{A}=1.77 \%$ for the volume mixing ratio of hematite. The agreement between the fitting curves and literature curves is satisfactory when considering the small sensitivity of radiance values to $m_{0}$ and $k_{0}$, and the derived values of $m_{0}$ and $k_{0}$ are consistent with reported values for silicate. The advantage of our dust model is that it can reproduce the important features of measured data in spite of the simplicity of the model, being based on just three parameters, $m_{0}, k_{0}$, and $\rho_{A}$. We have assumed internal mixing in Fig. 1 as the Maxwell-Garnett theory is applicable to dust particles having internal mixing. Although we tested another model assuming external mixing of silicate and hematite particles, the result exhibited much poorer agreement as compared with internal mixing treatment illustrated in Fig. 1.

Dust particles in the Martian atmosphere can possibly have various shapes, but limited information from direct observations (e.g., Pike et al. 2011) makes it difficult to theoretically formulate their shapes precisely. Moreover, it is difficult to reproduce the effects of non-spherical shapes in a radiative transfer simulation for the Martian atmosphere. To cope with these difficulties, here we propose the use of equivalent volume spheroids with random rotation axes as employed by Dubovik et al.

Table 1 Dust model parameters $\left(X_{1}-X_{7}\right)$

\begin{tabular}{llllllll}
\hline Parameter $(X)$ & $X_{a}$ & $X_{\min }$ & $X_{\max }$ & $\Delta X$ & $\Delta X / X_{a}$ & Reference \\
\hline$X_{1}$ & $\tau$ & 0.4 & 0.1 & 1.0 & 0.9 & 2.25 & 1 \\
$X_{2}$ & $r_{\text {eff }}$ & $1.6 \mu \mathrm{m}$ & $1.2 \mu \mathrm{m}$ & $2.0 \mu \mathrm{m}$ & $0.8 \mu \mathrm{m}$ & 0.5 & 2 \\
$X_{3}$ & $v_{\text {eff }}$ & 0.2 & 0.1 & 0.4 & 0.3 & 1.5 & 2 \\
$X_{4}$ & $\rho_{A}$ & 0.03 & 0 & 0.05 & 0.05 & 1.67 & 3 \\
$X_{5}$ & $m_{0}$ & 1.5 & 1.4 & 1.6 & 0.2 & 0.133 & 4 \\
$X_{6}$ & $k_{0}$ & 0.001 & 0 & 0.002 & 0.002 & 2 & 4 \\
$X_{7}$ & $z_{5}$ & $14 \mathrm{~km}$ & $5 \mathrm{~km}$ & $20 \mathrm{~km}$ & $15 \mathrm{~km}$ & 1.07 & 5 \\
\hline
\end{tabular}

References (1) Smith and Lemmon 1999; (2) Tomasko et al. 1999; (3) Ehlers et al. 2014; (4) Dabrowska et al. 2015; (5) Hoekzema et al. 2010.

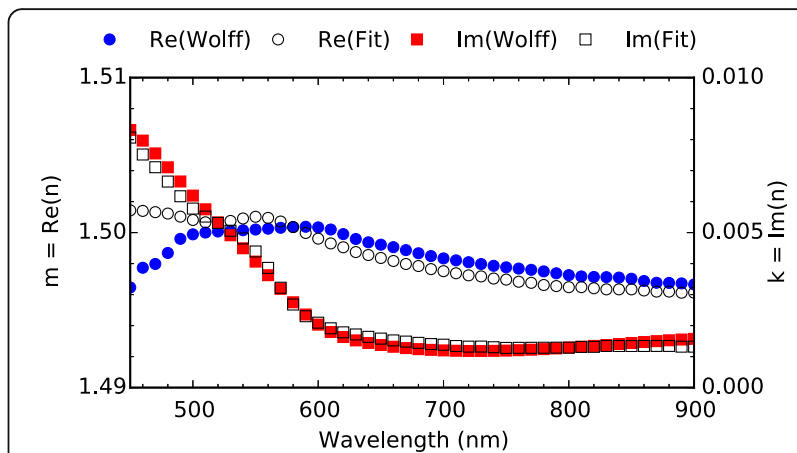

Fig. 1 Complex refractive index of Martian dust plotted against wavelength. Observational results (filled symbols) reported by Wolff et al. (2009) are compared with our fitting results (open symbo/s). In this example, the fitting leads to a silicate complex refractive index of $n_{0}=1.48-0.000942 i$ and a hematite volume mixing ratio of $\rho_{A}=1.77 \%$

(2006) to estimate the influence of particle shapes for feldspar samples collected from terrestrial soil. Similarly, here we fix the aspect ratio distribution in such a way that the distribution is zero at aspect ratios less than 1.44 , and gradually increases in the aspect ratio range between 1.44 and 3. A detailed discussion on the nonspherical shape effect will be given later. In general, when Maxwell-Garnett theory is applied to spheroids, the resulting RIs exhibit dependence on polarization. Such polarization dependence disappears only for the special case of spherical particles. Nevertheless, we assume the polarization-independent form of Eq. (1) for simplicity, though the light scattering calculations are implemented assuming non-spherical dust shapes.

In this research, we assume that the dust size distribution can be expressed with a monomodal gamma distribution including only coarse mode particles (Hansen and Travis 1974; Tomasko et al 1999). This assumption is based on the fact that for the optical properties of desert dust on the Earth, submicron (fine mode) particles can be ignored, and the size distribution can be treated as virtually monomodal, since most of particles are supermicron and in coarse mode (Dubovik et al. 2006). For completeness, the sensitivity of our model to the existence of fine mode particles will be discussed later. A monomodal gamma distribution can be expressed as

$$
\frac{\mathrm{d} N}{\mathrm{~d} \ln r}=\frac{r^{\xi}}{\left(r_{\mathrm{eff}} v_{\mathrm{eff}}\right)^{\xi} \Gamma(\xi)} \exp \left[-\frac{r}{r_{\mathrm{eff}} v_{\mathrm{eff}}}\right]
$$

with

$$
\xi=\frac{1}{v_{\text {eff }}}-2 .
$$

Here, $r$ is the particle radius and Nis the number of particles. The gamma function $(\Gamma)$ is used to normalize 
the integral of Eq. (2). Parameters $r_{\text {eff }}$ and $v_{\text {eff }}$ are the effective radius and effective variance, respectively, and they are defined as

$$
r_{\text {eff }}=\int_{-\infty}^{\infty} r^{3} \frac{\mathrm{d} N}{\mathrm{~d} \ln r} \mathrm{~d} \ln r /\left[\int_{-\infty}^{\infty} r^{2} \frac{\mathrm{d} N}{\mathrm{~d} \ln r} \mathrm{~d} \ln r\right]
$$

and

$$
v_{\text {eff }}=\int_{-\infty}^{\infty} r^{2}\left(r-r_{\text {eff }}\right)^{2} \frac{\mathrm{d} N}{\mathrm{~d} \ln r} \mathrm{~d} \ln r /\left[r_{\text {eff }}^{2} \int_{-\infty}^{\infty} r^{2} \frac{\mathrm{d} N}{\mathrm{~d} \ln r} \mathrm{~d} \ln r\right] .
$$

Since our observation is made optically, the most relevant parameter is the dust extinction coefficient $\left(\alpha_{e}\right)$, which is governed by the size distribution and extinction cross-section of dust particles. We consider the extinction value at wavelength $550 \mathrm{~nm}$, the peak wavelength of solar radiation. It is assumed that $\alpha_{e}$ is homogeneous horizontally, and it decreases exponentially with increasing altitude, $z$ :

$$
\alpha_{e}(z)=\frac{\tau}{z_{s}} \exp \left(-\frac{z}{z_{s}}\right) .
$$

Here, $\tau$ is the dust optical depth at wavelength $550 \mathrm{~nm}$ and $z_{s}$ is the scale height. The typical scale height of aerosols on the Earth is $\sim 2 \mathrm{~km}$. On the other hand, the scale height of Martian dust is typically $10-15 \mathrm{~km}$ (Thomas et al. 1999), which is similar to the scale height of pressure (Hoekzema et al. 2010), since the lower atmosphere is well-mixed on Mars. Besides, the variation range of optical depth of Martian dust is larger than that of terrestrial aerosols: namely, on Mars, typical values of $\tau$ are 0.2 (non-dimensional) for relatively clear periods, 1-2 for hot southern summers, and 4-5 during major dust storms (Savijärvi 2014).

In summary, our dust model can be described with only seven parameters: real $\left(m_{0}\right)$ and imaginary $\left(k_{0}\right)$ parts of RI of silicate substrate, volume mixing ratio of hematite inclusion $\left(\rho_{A}\right)$, effective radius $\left(r_{\text {eff }}\right)$ and effective variance $\left(v_{\text {eff }}\right)$ of size distribution, and optical depth $(\tau)$ and scale height $\left(z_{s}\right)$ of extinction coefficient at wavelength $550 \mathrm{~nm}$. Hereafter, these model parameters will be collectively denoted as $X$. Table 1 lists "a priori" (i.e., the most plausible value before observation, $X_{a}$ ), minimum values $\left(X_{\min }\right)$, maximum values $\left(X_{\max }\right)$, and variation ranges $\left(\Delta X=X_{\max }-X_{\min }\right)$ of the seven parameters utilized in the present model. When evaluating the impact of changes to dust model parameters, it is desirable that the parameters be normalized beforehand so that their variabilities will be on the same scale. Here, we use dust model parameters divided by the variation range $(\Delta X)$ listed in Table 1 . These normalized dust model parameters will be collectively denoted as $x$. The 7th column of Table 1 shows the ratio between $\Delta X$ and $X_{a}$, which will be used in our later analysis.

\section{Radiative transfer simulation of Martian atmosphere}

In this research, a radiative transfer simulation code, MODTRAN5 (Berk et al. 2006) is employed to calculate the theoretical spectra of DSR and SSR that would be observed by a Mars lander. Although MODTRAN is a simulation code originally developed for the terrestrial atmosphere, it is applicable to Martian atmosphere by changing parameters such as distance from the Sun and the concentrations of gas components. The main parameters to be configured for Mars are listed in Table 2. The atmosphere between 0 and $100 \mathrm{~km}$ is divided into 36 layers of stratified spherical atmosphere, with the assumption of horizontal uniformity. The use of the DISORT algorithm (Stamnes et al. 1988) is desirable for the detailed analysis of SSR in the observation data. In the present simulation study, however, we use Isaacs' two stream algorithm (Isaacs et al. 1987), which is much faster and the resulting differences in SSR values are estimated to be less than 20\% (Isaacs et al. 1987). The single scattering algorithm includes spherical geometry of ray transmission, while multiple scattering contributions are calculated using plane parallel geometry (the solar

\begin{tabular}{|c|c|}
\hline Item & Value \\
\hline Solar constant & $608 \mathrm{~W} / \mathrm{m}^{2}$ \\
\hline Radius of Mars & 3396 km \\
\hline Vertical profile of pressure & $\begin{array}{l}\text { Mean value of MCD } \\
\text { (7.6 hPa @ground) }\end{array}$ \\
\hline Vertical profile of temperature & $\begin{array}{l}\text { Mean value of MCD } \\
\text { (267 K @ground) }\end{array}$ \\
\hline $\mathrm{CO}_{2}$ volume mixing ratio & $95.32 \%$ \\
\hline $\mathrm{O}_{2}$ volume mixing ratio & $0.13 \%$ \\
\hline $\mathrm{O}_{3}$ volume mixing ratio & 30 ppb \\
\hline $\mathrm{H}_{2} \mathrm{O}$ volume mixing ratio & $\begin{array}{l}300 \mathrm{ppm}(<10 \mathrm{~km}) \\
0(>10 \mathrm{~km})\end{array}$ \\
\hline Volume mixing ratio of other gases & 0 \\
\hline $\begin{array}{l}\text { Vertical profile of dust extinction } \\
\text { coefficient }\end{array}$ & $\begin{array}{l}\text { Calculated from the } \\
\text { dust model }\end{array}$ \\
\hline $\begin{array}{l}\text { Wavelength dependence of dust } \\
\text { extinction }\end{array}$ & $\begin{array}{l}\text { Calculated from the } \\
\text { dust model }\end{array}$ \\
\hline $\begin{array}{l}\text { Wavelength dependence of dust } \\
\text { absorption }\end{array}$ & $\begin{array}{l}\text { Calculated from the } \\
\text { dust model }\end{array}$ \\
\hline $\begin{array}{l}\text { Wavelength/scattering angle } \\
\text { dependence of dust phase function }\end{array}$ & $\begin{array}{l}\text { Calculated from the } \\
\text { dust model }\end{array}$ \\
\hline Surface albedo & $\begin{array}{l}\text { Desert model } \\
(0.21 @ 450 \text { nm, } \\
0.34 @ 675 \text { nm) }\end{array}$ \\
\hline
\end{tabular}

Table 2 Main parameters of MODTRAN to be configured for Martian atmosphere

${ }^{\mathrm{a}} \mathrm{MCD}$ stands for the Mars Climate Database (Millour et al. 2012) 
illumination impinging upon each atmospheric level is determined with spherical refractive geometry). The extinction/absorption coefficients and phase function are calculated from the dust model by using a Fortran program developed by Dubovik et al. (2006); this software calculates optical parameters of spheroidal aerosols by using a look-up table prepared by coupling the T-matrix (Mishchenko and Travis 1998) and approximate geometric-optics integral-equation (Yang and Liou 1996) methods.

\section{Observational parameters for dust retrieval}

Spectral irradiance/radiance of DSR/SSR in the visible and near infrared spectral regions is to be measured with an environmental monitor camera onboard a Mars lander. Radiance values of SSR are measured at particular scattering angles $(\chi)$; the angle between the original solar ray (hitting the scattering particle) and the line of sight (LOS) from the particle to the observer). Here $X=$ 0 corresponds to scattering in the forward direction. The expressions $\operatorname{DSR}(\lambda)$ and $\operatorname{SSR}(\lambda, \chi)$ can be used to explicitly specify wavelength or scattering angle. To reduce the total volume of data that must be transmitted during the Mars observation mission, it is vitally important to minimize the number of quantities to be measured (i.e., the number of wavelengths and scattering angles) when designing an observation strategy.

Figure 2 summarizes the results of MODTRAN simulation, showing how the values of DSR/SSR depend on wavelength and scattering angle for various values of dust parameters $\left(\tau, r_{\text {eff }}, v_{\text {eff }}, \rho_{A}, m_{0}, k_{0}\right.$, and $\left.z_{s}\right)$. In Fig. 2a, $\mathrm{b}, \mathrm{DSR} / \mathrm{SSR}$ values are plotted for dust optical depths $(\tau)$ between 0.1 and 1. At all wavelengths between 400 and $900 \mathrm{~nm}$, decrease in DSR and increase in SSR are observed with increasing $\tau$. Among the seven dust model parameters, DSR shows almost no dependence on parameters other than $\tau$, whereas SSR changes with $\tau, r_{\text {eff }}$, $v_{\text {eff }}, \rho_{A}, m_{0}$, and $k_{0}$ (Fig. $2 \mathrm{~b}-\mathrm{g}$ ). Figure $2 \mathrm{c}$ shows that the SSR intensity of forward scattering $\left(\chi=3^{\circ}\right)$ increases at all wavelengths with increasing $r_{\text {eff }}$, while Fig. $2 d$ shows that the forward scattering intensity decreases over the absorption band of hematite (blue range around $450 \mathrm{~nm}$ ) with increasing $v_{\text {eff- }}$

Moreover, Fig. 2e, $\mathrm{f}$ shows that the SSR intensity of backward scattering $\left(X=120^{\circ}\right)$ decreases over the hematite absorption band with increasing $\rho_{A}$ and increasing $m_{0}$, while Fig. $2 \mathrm{~g}$ shows that the backward scattering intensity decreases at all wavelengths with increasing $k_{0}$. This is due to the fact that absorption is stronger at larger scattering angles due to longer effective path length. As seen from Fig. 2h, SSR is hardly affected by $z_{s}$, the dust scale height in the Martian atmosphere.
Thus, in order to derive all the necessary dust information while minimizing redundancy, we selected the wavelengths and scattering angles listed in Table 3 . The wavelength band width is chosen to be $10 \mathrm{~nm}$. The measurements of DSR spectra are made at the three wavelengths of $\left(\lambda_{0}, \lambda_{B}, \lambda_{R}\right)=(550,450,675)$ (in nm), while SSR spectra are measured at the two wavelengths of $\left(\lambda_{B}\right.$, $\left.\lambda_{R}\right)$ for the four scattering angles $\left(X_{0}, X_{\mathrm{A}}, X_{F}, X_{B}\right)=\left(10^{\circ}, 3^{\circ}\right.$, $\left.50^{\circ}, 120^{\circ}\right)$. As a result, 11 values are measured as listed in Table 4. The reason for the choices of $\lambda_{B}=450 \mathrm{~nm}$ within the hematite absorption band and $\lambda_{R}=675 \mathrm{~nm}$ outside the band is that these wavelengths are close to the peak wavelength of SSR radiance $(\sim 550 \mathrm{~nm})$ with reasonable sensitivity of a silicon sensor. As shown in Fig. 3, the measurement of SSR is carried out on the almucantar plane $\left(\theta_{\text {los }}=\theta_{\text {sun }}\right)$, where LOS zenith angle $\left(\theta_{\text {los }}\right)$ is the same as the solar zenith angle $\left(\theta_{\text {sun }}\right)$. When $x>2 \theta_{\text {sun }}$, on the other hand, SSR is measured on the principal plane $\left(\theta_{\mathrm{los}}=\chi-\theta_{\text {sun }}, \phi_{\text {los }}=\phi_{\text {sun }}+180^{\circ}\right)$, where LOS azimuth angle $\left(\phi_{\text {los }}\right)$ is on the opposite side of the solar azimuth direction $\left(\phi_{\text {sun }}\right)$.

So far, we have considered how to choose the minimal set of quantities to be measured that satisfies the necessary and sufficient conditions for estimating the dust model parameters. Additionally, we have to avoid the influence of measurement error as far as possible. For this purpose, the use of relative values of spectral irradiance/radiance, instead of their absolute values, is advantageous for improving the accuracy of the resulting dust parameters, since precise calibration of a lander camera is difficult and the relative values are less sensitive to calibration errors than absolute values. Therefore, in this research, we calculated the appropriate ratios among the 11 measured quantities listed in Table 4, and we propose the final observational parameter set as listed in Table 5 . In the second column of this table, the capital letters, $D, A, F$, and $B$ indicate direct solar radiation, aureole (i.e., scattered solar radiation in close vicinity to the Sun), forward scattering, and backward scattering, respectively, and the subscripts $0, C, B$, and $R$ indicate values at the reference wavelength $(550 \mathrm{~nm})$, color ratio (i.e., intensity ratio of blue to red), values at the blue wavelength $(450 \mathrm{~nm})$, and values at the red wavelength $(675 \mathrm{~nm})$, respectively.

Hereafter, raw values of measured quantities and observational parameters will be written in upper-case letters as $P$ and $Y$, respectively. As in the case of the dust model parameters, we use normalized values of $P$ and $Y$ in order to evaluate their sensitivities. Since relative errors of spectral measurements are expected to be comparable with each other, we use measured quantities divided by the values calculated with a priori model parameters. These normalized measured 
(a) $\tau$

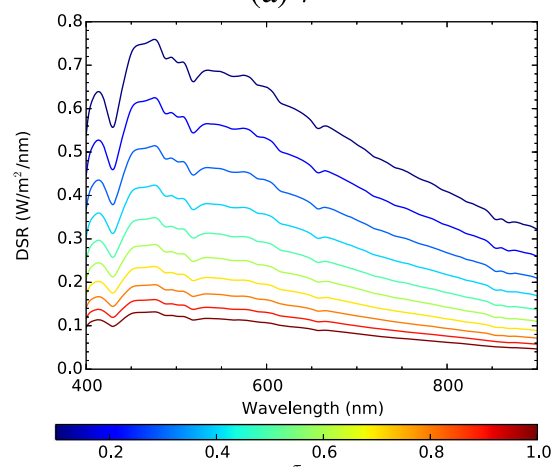

(c) $r_{\text {eft }}$
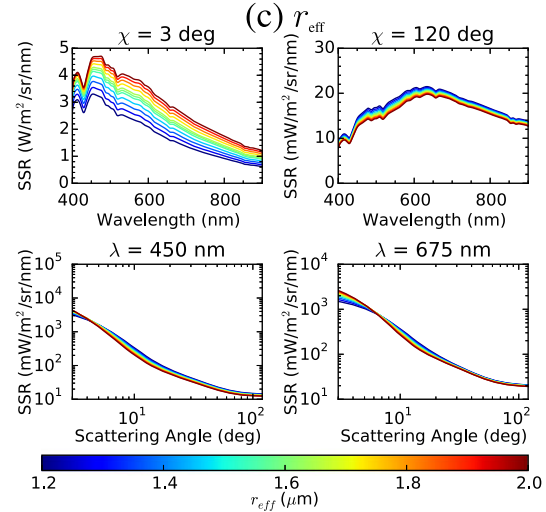

(e) $\rho_{A}$
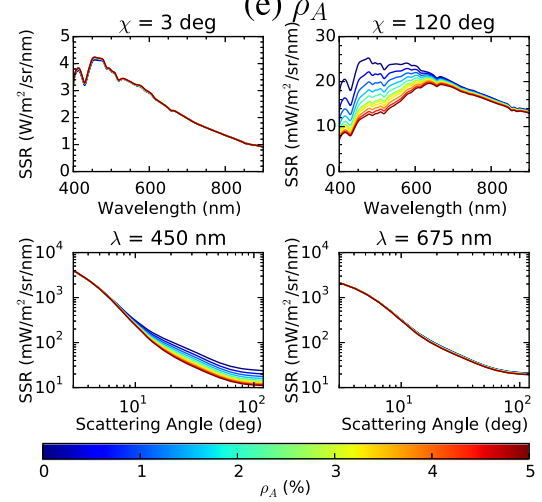

(g) $k_{0}$
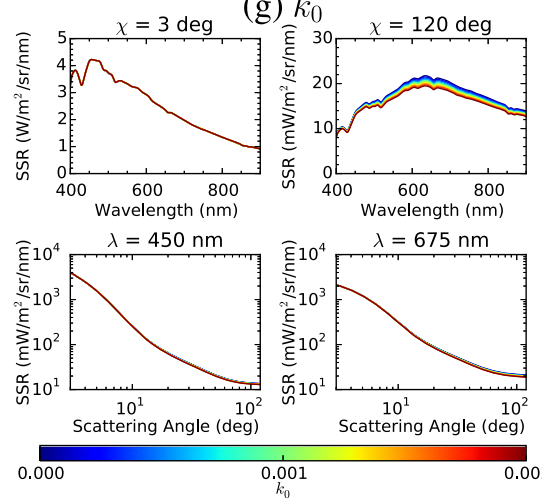

(b) $\tau$
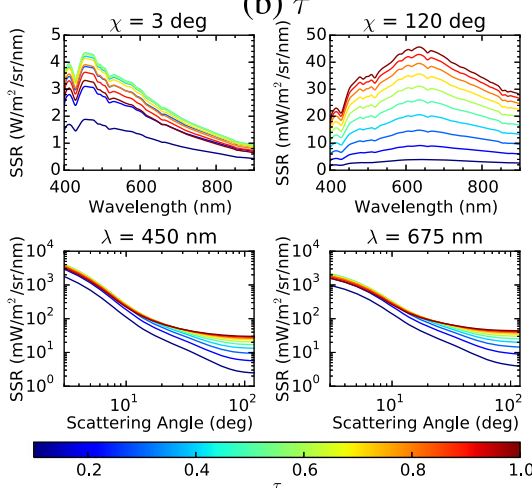

(d) $v_{\text {es }}$
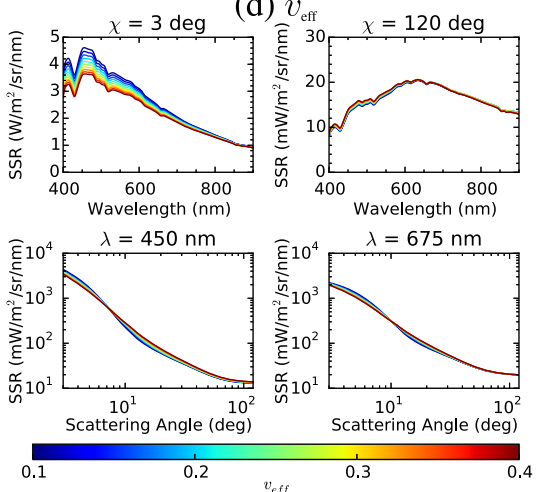

(f) $m_{0}$
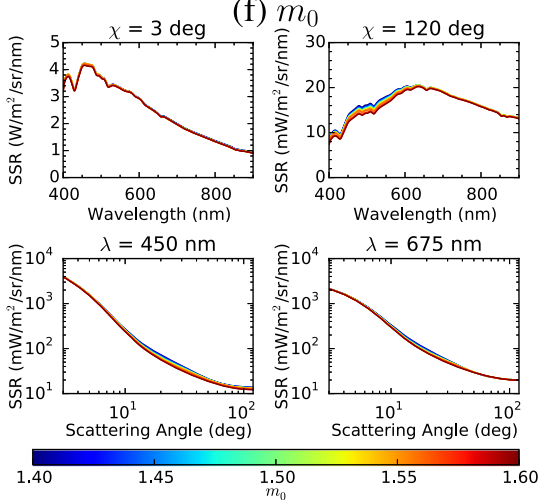

(h) $z_{s}$
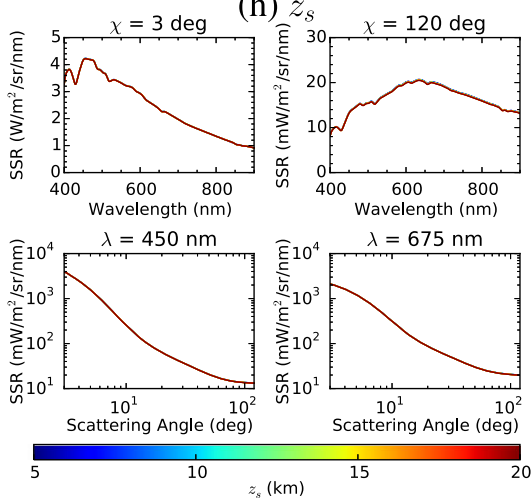

Fig. 2 Sensitivity of (a) DSR and ( $\mathbf{b}-\mathbf{h})$ SSR to dust model parameters. DSR and SSR intensities for various values of dust model parameters ( $a: \tau, b: \tau, c$ : $r_{\text {eff, }} d: v_{\text {eff, }} e: \rho_{A}, f: m_{0}, g: k_{0}, h: z_{S}$ ) calculated with a radiative transfer code (MODTRAN5) are plotted as functions of wavelength or scattering angle 
Table 3 Wavelengths and scattering angles chosen for dust observation

\begin{tabular}{lllll}
\hline Parameter & & Description & Value & DSR \\
\hline Wavelength & $\lambda_{0}$ & Reference wavelength & $550 \mathrm{~nm}$ & $\checkmark$ \\
& $\lambda_{B}$ & Inside absorption band of hematite & $450 \mathrm{~nm}$ & $\checkmark$ \\
Scattering angle & $\lambda_{R}$ & Outside absorption band of hematite & $675 \mathrm{~nm}$ & $\checkmark$ \\
& $X_{0}$ & Reference scattering angle & $10^{\circ}$ & $\checkmark$ \\
& $X_{A}$ & Aureole scattering angle & $3^{\circ}$ & $\checkmark$ \\
& $X_{F}$ & Forward scattering angle & $50^{\circ}$ & $\checkmark$ \\
& $X_{B}$ & Backward scattering angle & $120^{\circ}$ & $\checkmark$ \\
\hline
\end{tabular}

quantities will be denoted in lower-case letters as $p$, and observational parameters calculated with the normalized measured quantities will be denoted as $y$.

\section{Observational parameters for water vapor retrieval}

Water vapor absorption bands are located inside the sensitive range (350-1000 nm) of conventional complementary metal-oxide semiconductor (CMOS) sensors to be employed for our environmental monitor camera. By measuring the absorbance in DSR or SSR spectra, we can measure TCWV $\left(c_{w}\right)$ through the Martian atmosphere, where the water vapor concentration is very limited $(\sim 300 \mathrm{ppm})$. Among the nearinfrared absorption bands, it would be reasonable to employ the strongest absorption band around 930$970 \mathrm{~nm}$. Here, we assume the atmospheric model parameters listed in Table 2, and we calculate the value of $c_{w}$ by assuming that the volume mixing ratio (VMR) of water vapor is constant below $10 \mathrm{~km}$. The a priori value of $c_{w}$ is $1.43 \mathrm{mg} / \mathrm{cm}^{2}$ for a water vapor VMR of $300 \mathrm{ppm}$. Figure 4 shows transmittance spectra simulated at a solar zenith angle (SZA) of $80^{\circ}$ while changing the water vapor VMR as 100, 300, and $500 \mathrm{ppm}$.

In this study, we calculate values of $c_{w}$ from the ratio of DSR or SSR at wavelengths inside and outside the water vapor absorption band. Here, we consider the wavelengths and the scattering angles listed in Table 6 . The wavelength band width is chosen to be $5 \mathrm{~nm}$. Since the effective optical path length is larger

Table 4 Measured quantities $\left(P_{1}-P_{11}\right)$ of DSR and SSR for dust retrieval

\begin{tabular}{llll}
\hline Parameter $(P)$ & Measured quantity & Parameter $(P)$ & Measured quantity \\
\hline$P_{1}$ & $\operatorname{DSR}\left(\lambda_{0}\right)$ & $P_{7}$ & $\operatorname{SSR}\left(\lambda_{B}, X_{B}\right)$ \\
$P_{2}$ & $\operatorname{DSR}\left(\lambda_{B}\right)$ & $P_{8}$ & $\operatorname{SSR}\left(\lambda_{R}, X_{0}\right)$ \\
$P_{3}$ & $\operatorname{DSR}\left(\lambda_{R}\right)$ & $P_{9}$ & $\operatorname{SSR}\left(\lambda_{R}, X_{A}\right)$ \\
$P_{4}$ & $\operatorname{SSR}\left(\lambda_{B}, X_{0}\right)$ & $P_{10}$ & $\operatorname{SSR}\left(\lambda_{R}, X_{F}\right)$ \\
$P_{5}$ & $\operatorname{SSR}\left(\lambda_{B}, X_{A}\right)$ & $P_{11}$ & $\operatorname{SSR}\left(\lambda_{R}, X_{B}\right)$ \\
$P_{6}$ & $\operatorname{SSR}\left(\lambda_{B}, X_{F}\right)$ & & \\
\hline
\end{tabular}

at larger scattering angles, the line-of-sight directions of $\theta_{\text {los }}=85^{\circ}$ and $\phi_{\text {los }}=\phi_{\text {sun }}+180^{\circ}$ have been chosen for the SSR measurements.

The measured quantities $\left(P_{12}-P_{17}\right)$ are listed in Table 7 , and they are appropriately combined to define the observational parameters as listed in Table 8 . When only two wavelengths are available, the outside wavelength should be chosen to be $\lambda_{S}=925 \mathrm{~nm}$,

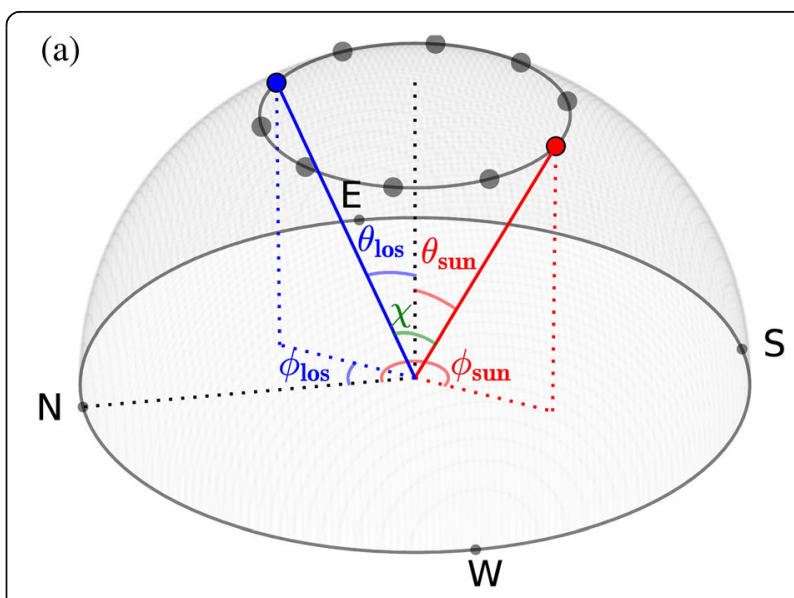

(b)

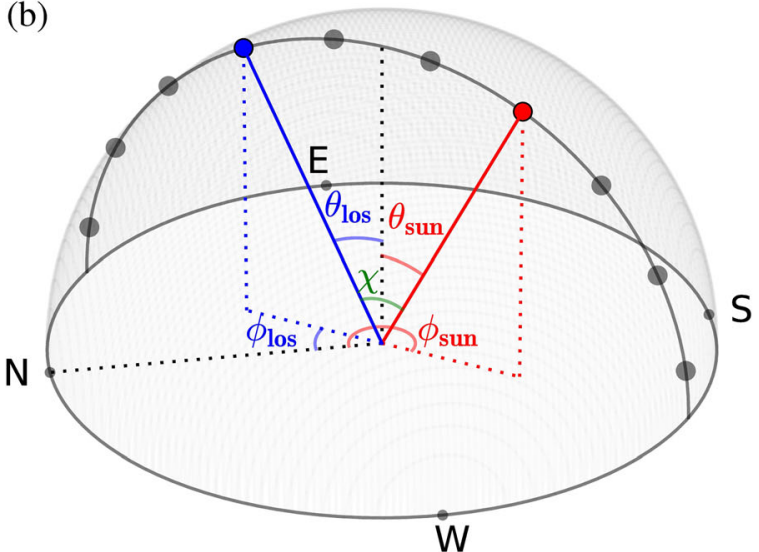

Fig. 3 Schematic figures of observation geometry on (a) almucantar plane and (b) principle plane 
Table 5 Observational parameters $\left(Y_{1}-Y_{11}\right)$ used for dust retrieval

\begin{tabular}{|c|c|c|c|}
\hline \multicolumn{2}{|c|}{ Parameter $(Y)$} & \multicolumn{2}{|c|}{ Relationship with measured quantities } \\
\hline$\overline{Y_{1}}$ & $D_{0}$ & $P_{1}$ & $\operatorname{DSR}\left(\lambda_{0}\right)$ \\
\hline$Y_{2}$ & $D_{C}$ & $P_{2} / P_{3}$ & $\operatorname{DSR}\left(\lambda_{B}\right) / \operatorname{DSR}\left(\lambda_{R}\right)$ \\
\hline$Y_{3}$ & $A_{C}$ & $P_{5} / P_{9}$ & $\operatorname{SSR}\left(\lambda_{B}, X_{A}\right) / \operatorname{SSR}\left(\lambda_{R_{1}}, X_{A}\right)$ \\
\hline$Y_{4}$ & $A_{B}$ & $P_{5} / P_{4}$ & $\operatorname{SSR}\left(\lambda_{B}, X_{A}\right) / \operatorname{SSR}\left(\lambda_{B}, X_{0}\right)$ \\
\hline$Y_{5}$ & $A_{R}$ & $P_{9} / P_{8}$ & $\operatorname{SSR}\left(\lambda_{R_{1}}, X_{A}\right) / \operatorname{SSR}\left(\lambda_{R_{1}} X_{0}\right)$ \\
\hline$Y_{6}$ & $F_{C}$ & $P_{6} / P_{10}$ & $\operatorname{SSR}\left(\lambda_{B}, X_{F}\right) / \operatorname{SSR}\left(\lambda_{R}, X_{F}\right)$ \\
\hline$Y_{7}$ & $F_{B}$ & $P_{6} / P_{4}$ & $\operatorname{SSR}\left(\lambda_{B}, X_{F}\right) / \operatorname{SSR}\left(\lambda_{B}, X_{0}\right)$ \\
\hline$Y_{8}$ & $F_{R}$ & $P_{10} / P_{8}$ & $\operatorname{SSR}\left(\lambda_{R}, X_{F}\right) / \operatorname{SSR}\left(\lambda_{R}, X_{0}\right)$ \\
\hline$Y_{9}$ & $B_{C}$ & $P_{7} / P_{11}$ & $\operatorname{SSR}\left(\lambda_{B}, X_{B}\right) / \operatorname{SSR}\left(\lambda_{R}, X_{B}\right)$ \\
\hline$Y_{10}$ & $B_{B}$ & $P_{7} / P_{4}$ & $\operatorname{SSR}\left(\lambda_{B}, X_{B}\right) / \operatorname{SSR}\left(\lambda_{B}, X_{0}\right)$ \\
\hline$Y_{11}$ & $B_{R}$ & $P_{11} / P_{8}$ & $\operatorname{SSR}\left(\lambda_{R}, X_{B}\right) / \operatorname{SSR}\left(\lambda_{R}, X_{0}\right)$ \\
\hline
\end{tabular}

which is closer to $\lambda_{W}=935 \mathrm{~nm}$. Then, $c_{w}$ is optimized by matching the calculated ratio of $D_{2}=\operatorname{DSR}\left(\lambda_{W}\right) /$ $\operatorname{DSR}\left(\lambda_{S}\right)$ or similar ratio of $\operatorname{SSR}\left(S_{2}\right)$ to the measured one. Alternatively, when three wavelengths are available, non-absorptive wavelengths are chosen at wavelengths shorter $\left(\lambda_{S}=925 \mathrm{~nm}\right)$ and longer $\left(\lambda_{L}=\right.$ $972 \mathrm{~nm})$ than the absorption band. By linear interpolation, a reference intensity at $\lambda_{W}\left(\operatorname{DSR}_{0}\left(\lambda_{W}\right)\right.$ $=\left[\left(\lambda_{L}-\lambda_{W}\right) \operatorname{DSR}\left(\lambda_{S}\right)+\left(\lambda_{W}-\lambda_{S}\right) \operatorname{DSR}\left(\lambda_{L}\right)\right] /\left(\lambda_{L}-\lambda_{S}\right)$ and similar value for SSR) can be obtained that is free of water vapor absorption. Then, $c_{w}$ is found by matching the calculated ratio $D_{3}=\operatorname{DSR}\left(\lambda_{W}\right) / \operatorname{DSR}_{0}\left(\lambda_{W}\right)$ or a similar one for SSR $\left(S_{3}\right)$ to the measured ratio. Using three wavelengths, more precise estimation of water vapor absorption is possible with better knowledge of the spectral intensity covering the entire range around the absorption band.

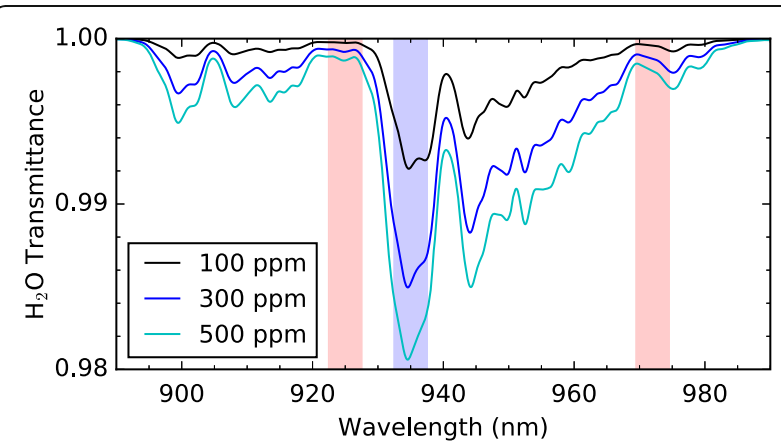

Fig. 4 Transmittance of water vapor in the Martian atmosphere. Values are simulated with a wavelength resolution of $2 \mathrm{~nm}$ (FWHM) for volume concentrations of 100,300, and 500 ppm. The blue band indicates the wavelength band around the absorption peak centered at $935 \mathrm{~nm}$ with a band width of $5 \mathrm{~nm}$, and the two red bands indicate the wavelength band outside the absorption band centered at 935 and $972 \mathrm{~nm}$ with a band width of $5 \mathrm{~nm}$

\section{Retrieval of model parameters}

We consider the optimization of model parameters (including both dust model parameters and TCWV) through a least squares analysis. We assume a form of

$$
\boldsymbol{y}=\boldsymbol{F}(\boldsymbol{x})+\boldsymbol{\varepsilon}_{y},
$$

where $\boldsymbol{x}$ and $\boldsymbol{y}$ are vectors composed of the normalized values of model parameters and observational parameters, respectively, $\boldsymbol{F}(\boldsymbol{x})$ is a forward model function, and $\boldsymbol{\varepsilon}_{y}$ is measurement noise. The Taylor series expansion of Eq. (7) around the a priori value $\boldsymbol{x}_{a}$ leads to the linear approximation given as

$$
\boldsymbol{y}=\boldsymbol{F}\left(\boldsymbol{x}_{a}\right)+\boldsymbol{K}_{x}\left(\boldsymbol{x}-\boldsymbol{x}_{a}\right)+\boldsymbol{\varepsilon}_{y}
$$

Here, $\boldsymbol{K}_{x}=\partial(\boldsymbol{x}) / \partial \boldsymbol{x}$ is the Jacobian matrix. If we ignore measurement noise, Eq. (8) can be solved using a pseudo-inverse matrix of $\boldsymbol{K}_{x}$. In reality, however, measurement noise is not negligibly small. In order to avoid the instability of the solution due to a lack of sufficient information from the observation, we consider the following cost function that includes the residuals of both the observational and model parameters:

$$
\begin{aligned}
c(\boldsymbol{x})= & (\boldsymbol{y}-\boldsymbol{F}(\boldsymbol{x}))^{\mathrm{T}} \boldsymbol{S}_{y}^{-1}(\boldsymbol{y}-\boldsymbol{F}(\boldsymbol{x})) \\
& +\left(\boldsymbol{x}-\boldsymbol{x}_{a}\right)^{\mathrm{T}} \boldsymbol{S}_{a}^{-1}\left(\boldsymbol{x}-\boldsymbol{x}_{a}\right) .
\end{aligned}
$$

Here, $\boldsymbol{S}_{y}$ and $\boldsymbol{S}_{a}$ are the variance-covariance matrices of the observational parameters and a priori of the model parameters, respectively. The $(i, j)$ element of $\boldsymbol{S}_{y}$ is the covariance of $y_{i}$ and $y_{j}$, which is $\left\langle\left(y_{i}-\left\langle y_{i}\right\rangle\right)\left(y_{j}-\right.\right.$ $\left.\left.\left\langle y_{j}\right\rangle\right)\right\rangle$, where $\left\langle y_{i}\right\rangle$ stands for the expectation value of $y_{i}$ ( $1 \leq i \leq 11$, see Table 5 for the case of dust retrieval). The $i$-th diagonal element of $S_{y}$ represents the variance of $y_{i}$, i.e. $\left\langle\left(y_{i}-\left\langle y_{i}\right\rangle\right)^{2}\right\rangle$. Similarly, the off-diagonal and diagonal elements of $S_{a}$ represent the covariance and variance of a priori, respectively. We optimize the model parameters by minimizing the cost function with iterative calculation based on the non-linear least square method (Rodgers, 2000).

\section{Linear approximation for error estimation}

In the following discussion on the retrieval error, for simplicity, we use a linear approximation (the Jacobian is calculated with the a priori). The expectation value (retrieved solution, $\boldsymbol{x}_{r}$ ) of the model parameters can be given as

$$
\boldsymbol{x}_{r}=\boldsymbol{x}_{a}+\left(\boldsymbol{K}_{x}^{\mathrm{T}} \boldsymbol{S}_{y}^{-1} \boldsymbol{K}_{x}+\boldsymbol{S}_{a}^{-1}\right)^{-1} \boldsymbol{K}_{x}^{\mathrm{T}} \boldsymbol{S}_{y}^{-1}\left(\boldsymbol{y}-\boldsymbol{F}\left(\boldsymbol{x}_{a}\right)\right)
$$

Here, we have assumed that the errors of observational and model parameters follow Gaussian distributions. 
Table 6 Wavelengths and a scattering angle chosen for TCWV measurement

\begin{tabular}{llll}
\hline Parameter & & Description & Value \\
\hline Wavelength & $\lambda_{W}$ & Peak wavelength of water vapor absorption & $935 \mathrm{~nm}$ \\
& $\lambda_{S}$ & Shorter wavelength outside absorption band of water vapor & $925 \mathrm{~nm}$ \\
Scattering angle & $\lambda_{L}$ & Longer wavelength outside absorption band of water vapor & $972 \mathrm{~nm}$ \\
\hline
\end{tabular}

Defining a gain matrix as $\boldsymbol{G}_{y}=\partial \boldsymbol{x}_{r} / \partial \boldsymbol{y}=\left(\boldsymbol{K}_{x}^{T} \boldsymbol{S}_{y}^{-1} \boldsymbol{K}_{x}+\boldsymbol{S}_{a}^{-1}\right)^{-1}$ $\boldsymbol{K}_{x}^{T} \boldsymbol{S}_{y}^{-1}$, we can rewrite Eq. (10) as

$$
\boldsymbol{x}_{r}=\boldsymbol{x}_{a}+\boldsymbol{G}_{y}\left(\boldsymbol{y}-\boldsymbol{F}\left(\boldsymbol{x}_{a}\right)\right) .
$$

Furthermore, using $\boldsymbol{A}=\partial \boldsymbol{x}_{r} / \partial \boldsymbol{y}=\boldsymbol{G}_{y} \boldsymbol{K}_{x}=\left(\boldsymbol{K}_{x}^{T} \boldsymbol{S}_{y}^{-1} \boldsymbol{K}_{x}+\boldsymbol{S}_{a}^{-1}\right)^{-1}$ $\boldsymbol{K}_{x}^{T} \boldsymbol{S}_{y}^{-1} \boldsymbol{K}_{x}$ and $\boldsymbol{G}_{a}=\partial \boldsymbol{x}_{r} / \partial \boldsymbol{x}_{a}=\left(\boldsymbol{I}_{n}-\boldsymbol{A}\right)=\left(\boldsymbol{K}_{x}^{T} \boldsymbol{S}_{y}^{-1} \boldsymbol{K}_{x}+\boldsymbol{S}_{a}^{-1}\right)^{-1}$ $\boldsymbol{S}_{a}^{-1}$, we can rewrite Eq. (11) as

$$
\boldsymbol{x}_{r}=\boldsymbol{A} \boldsymbol{x}+\boldsymbol{G}_{a} \boldsymbol{x}_{a} .
$$

In Eq. (12), the right-hand side can be regarded as a weighted mean of the model parameter obtained from the true state $(\boldsymbol{x})$ and the a priori $\left(\boldsymbol{x}_{a}\right)$, with weights of $\boldsymbol{K}_{x}^{T} \boldsymbol{S}_{y}^{-1} \boldsymbol{K}_{x}$ and $\boldsymbol{S}_{a}^{-1}$, respectively. Here, $\boldsymbol{A}$ is a matrix called the averaging kernel matrix (AKM), its diagonal elements indicating the extent to which the true model parameters affect the retrieved solution.

\section{Adjustment of regularization strength}

The weight of the a priori is determined by the balance between $S_{y}$ and $S_{a}$. From a statistical point of view, the optimum value of $S_{a}$ would be the actual variancecovariance matrix of a priori $\left(\boldsymbol{S}_{e}\right)$. However, it is difficult to estimate $S_{e}$ accurately. In some cases, better solutions can be obtained by using $S_{a}$ that are different from $\boldsymbol{S}_{e}$ and adjusting the strength of regularization (i.e., constraint from the a priori data). Here, we introduce a regularization parameter $\gamma$ as

$$
\boldsymbol{S}_{a^{-1}}=\gamma \boldsymbol{S}_{e}^{-1}
$$

The regularization strength is increased by increasing the value of $\gamma$. When we increase the regularization parameter, at some point the weight on the a priori becomes non-negligible and the retrieved parameter tends to be drawn toward its a priori value. This results in a gradual increase in the residuals of the observational parameters, since in general, a priori values are different from true values. In accordance with Tikhonov

Table 7 Measured quantities $\left(P_{12}-P_{17}\right)$ of DSR and SSR for TCW retrieval

\begin{tabular}{llll}
\hline Parameter $(P)$ & Measured quantity & Parameter $(P)$ & Measured quantity \\
\hline$P_{12}$ & $\operatorname{DSR}\left(\lambda_{W}\right)$ & $P_{15}$ & $\operatorname{SSR}\left(\lambda_{W}, X_{W}\right)$ \\
$P_{13}$ & $\operatorname{DSR}\left(\lambda_{S}\right)$ & $P_{16}$ & $\operatorname{SSR}\left(\lambda_{S_{1}}, X_{W}\right)$ \\
$P_{14}$ & $\operatorname{DSR}\left(\lambda_{L}\right)$ & $P_{17}$ & $\operatorname{SSR}\left(\lambda_{L}, X_{W}\right)$ \\
\hline
\end{tabular}

regularization (Doicu et al. 2010), a good regularization strength is achieved by making it stronger within the range in which the residuals of observational parameters, i.e., the first term of the cost function (9), are almost constant.

\section{Error estimation of model parameters}

First, we consider the errors in the retrieved model parameters propagated from both measured values and a priori values. A variance-covariance matrix of the model parameters due to propagation error of measurement $\left(\boldsymbol{S}_{m}\right)$ can be calculated as

$$
\boldsymbol{S}_{m}=\boldsymbol{G}_{y} \boldsymbol{S}_{y} \boldsymbol{G}_{y}^{\mathrm{T}}
$$

Similarly, a variance-covariance matrix of model parameters due to a priori error $\left(\boldsymbol{S}_{s}\right)$ can be obtained using $\boldsymbol{G}_{a}=\boldsymbol{I}_{n}-\boldsymbol{A}$ as

$$
\boldsymbol{S}_{s}=\boldsymbol{G}_{a} \boldsymbol{S}_{e} \boldsymbol{G}_{a}^{\mathrm{T}} .
$$

The combined variance-covariance matrix of model parameters including both measurement error and a priori error is given as

$$
\boldsymbol{S}_{c}=\boldsymbol{S}_{m}+\boldsymbol{S}_{s}
$$

The equation $\boldsymbol{S}_{c}=\left(\boldsymbol{K}_{x}^{\mathrm{T}} \boldsymbol{S}_{y}^{-1} \boldsymbol{K}_{x}+\boldsymbol{S}_{a}^{-1}\right)^{-1}$ holds when $\gamma=1$. If we define error ratio $\boldsymbol{\varepsilon}_{r}$ as

$$
\begin{aligned}
\boldsymbol{\varepsilon}_{r} & =\left[\operatorname{diag}\left(\boldsymbol{S}_{s} \boldsymbol{S}_{c}^{-1}\right)\right]^{1 / 2} \\
& =\left[\operatorname{diag}\left(\boldsymbol{G}_{a} \gamma\left(\boldsymbol{A}+\boldsymbol{G}_{a} \gamma\right)^{-1}\right)\right]^{1 / 2}
\end{aligned}
$$

then we have $\boldsymbol{\varepsilon}_{r}=\left[\operatorname{diag}\left(\boldsymbol{G}_{a}\right)\right]^{1 / 2}$ when $\gamma=1$. Each element of $\boldsymbol{\varepsilon}_{r}$ changes from 0 to 1 when $\gamma$ changes from 0 to $\infty$. In addition to the propagation errors described above, imperfectness of the forward model can cause systematic errors. Systematic errors of retrieved model parameters $\left(\boldsymbol{\varepsilon}_{x}\right)$ due to estimation errors of the forward model in the observational parameters $\left(\boldsymbol{\varepsilon}_{f}\right)$ can be estimated as

$$
\boldsymbol{\varepsilon}_{x}=\boldsymbol{G}_{y} \boldsymbol{\varepsilon}_{f}
$$

\section{Results and discussion}

\section{Sensitivity analysis of observational parameters}

In order to examine the sensitivity of observational parameters ( $Y$ in Table 5$)$ to the dust model parameters $(X$ in Table 1), we changed the values of $X$ from the 
Table 8 Observational parameters $\left(Y_{12}-Y_{15}\right)$ for TCWV retrieval

\begin{tabular}{llll}
\hline Parameter $(Y)$ & \multicolumn{3}{l}{ Relationship with measured quantities } \\
\hline$Y_{12}$ & $D_{2}$ & $P_{12} / P_{13}$ & $\operatorname{DSR}\left(\lambda_{W}\right) / \operatorname{DSR}\left(\lambda_{S}\right)$ \\
$Y_{13}$ & $S_{2}$ & $P_{15} / P_{16}$ & $\operatorname{SSR}\left(\lambda_{W}, X_{W}\right) / \operatorname{SSR}\left(\lambda_{S}, X_{W}\right)$ \\
$Y_{14}$ & $D_{3}$ & $P_{12} /\left[a P_{13}+\beta P_{14}\right]$ & $\operatorname{DSR}\left(\lambda_{W}\right) /\left[a \operatorname{DSR}\left(\lambda_{S}\right)+\beta \operatorname{DSR}\left(\lambda_{L}\right)\right]$ \\
$Y_{15}$ & $S_{3}$ & $P_{15} /\left[a P_{16}+\beta P_{17}\right]$ & $\operatorname{SSR}\left(\lambda_{W}, X_{W}\right) /\left[a \operatorname{SSR}\left(\lambda_{S}, X_{W}\right)+\beta \operatorname{SSR}\left(\lambda_{L}, X_{W}\right)\right]$ \\
\hline
\end{tabular}

$a=\left(\lambda_{L}-\lambda_{W}\right) /\left(\lambda_{L}-\lambda_{S}\right), \beta=\left(\lambda_{W}-\lambda_{S}\right) /\left(\lambda_{L}-\lambda_{S}\right)$

minimum to the maximum (see Table 1) and calculated the variation range of $\boldsymbol{Y}$. Only one dust model parameter was changed at a time, with other parameters fixed to their a priori values. The results of this sensitivity analysis are summarized in Fig. 5a-n.

Figure $5 \mathrm{a}-\mathrm{g}$ shows the results for normalized observational parameters $(y)$ obtained with the SZA fixed at $60^{\circ}$, which is a typical value as indicated in the results shown below. The scales of the vertical axes are the same for these panels except for Fig. 5a. Figure 5a-g indicates that the present choice of observational parameters has led to reasonably large sensitivity (more than $30 \%$ of observational parameters calculated with the a priori) to $\tau$, $r_{\text {eff, }}, v_{\text {eff, }}$ and $\rho_{A}$, relatively small sensitivity to $m_{0}$ and $k_{0}$, and much less sensitivity to $z_{s}$. In Fig. $5 \mathrm{a}-\mathrm{d}$, most of the resulting curves show linear (or nearly linear) responses, though some non-linear features are seen as in the case of $D_{0}$ vs. $\tau$ in Fig. $5 \mathrm{a}$.

In Fig. $5 \mathrm{~h}-\mathrm{n}$, the results for variation range $(\Delta y)$ are plotted as functions of SZA. Here, $\Delta y$ stands for the maximum minus the minimum value $(\Delta y>0)$ if the observational parameter increases with increasing model parameter, otherwise the minimum minus the maximum $(\Delta y<0)$. For instance, $\Delta D_{0}(\tau)$ in Fig. $5 \mathrm{~h}$ shows the SZA dependence of the difference between the minimum $D_{0}$ and maximum $D_{0}$ when $\tau$ is changed between 0.1 and 1 , as indicated in Fig. 5a (for SZA $=60^{\circ}$ ). Such graphs are useful for estimating how the sensitivity changes with the time of DSR/SSR observations. Although in most cases no dependence on SZA can be seen, in some cases such as $D_{0}$ vs. $\tau$, a certain increase in variation (sensitivity) is found with increasing SZA. This is ascribable to the longer path of DSR in the dust layer under large SZA conditions, namely, at dusk and dawn.

For better retrieval of each model parameter, it is required for an observational parameter to have a large sensitivity to that model parameter. It is also desirable that it exhibit sensitivity solely to that specific model parameter, not being affected by other model parameters. For example, $D_{0}=\operatorname{DSR}\left(\lambda_{0}\right)$ has sensitivity solely to $\tau$; thus, the aerosol optical depth, $\tau$, is well retrieved from the DSR measurement. Similarly, the dust effective radius, $r_{\text {eff }}$, can be retrieved from $A_{R}=\operatorname{SSR}\left(\lambda_{R}, \chi_{\mathrm{A}}\right) /$ $\operatorname{SSR}\left(\lambda_{R}, \chi_{0}\right)$, the hematite volume mixing ratio, $\rho_{A}$, from $F_{C}=\operatorname{SSR}\left(\lambda_{B}, X_{F}\right) / \operatorname{SSR}\left(\lambda_{R}, \chi_{F}\right)$, and if $r_{\text {eff }}$ and $\rho_{A}$ are already known, the width parameter of size distribution, $v_{\text {eff }}$, can be obtained from $A_{B}=\operatorname{SSR}\left(\lambda_{B}, \chi_{\mathrm{A}}\right) / \operatorname{SSR}\left(\lambda_{B}, \chi_{0}\right)$. Therefore, the combination of observational parameters listed in Table 4 can provide information sufficient for

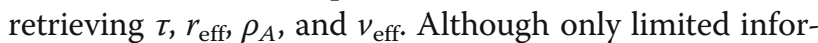
mation on dust scale height $\left(z_{s}\right)$ can be obtained from our retrieval, it is necessary to include $z_{s}$ in our retrieval procedure so as to examine the influence of $z_{s}$ on the retrieval of other dust model parameters. A detailed discussion on the information content of each dust model parameter will be given later.

\section{Error estimation for dust measurement}

In the following discussion, for simplicity, it is assumed that all measured quantities ( $P$ in Table 4 ) have the same relative error, and the propagation errors of observational parameters ( $Y$ in Table 5) are estimated by giving a reasonably small relative error of $1 \%$. Since random noise is considered in the measured quantities, the variance-covariance matrix of measured quantities $\left(S_{p}\right)$ is assumed to be diagonal. Errors in the normalized measured quantities $(p)$ propagate to the normalized observational parameters $(y)$ according to the Jacobian matrix $\boldsymbol{K}_{p}=\partial \boldsymbol{y} / \partial \boldsymbol{p}$ and the variance-covariance matrix can be calculated as $\boldsymbol{S}_{y}=\boldsymbol{K}_{p} \boldsymbol{S}_{p} \boldsymbol{K}_{p}^{\mathrm{T}}$. Although this matrix can be non-diagonal, we retain only the diagonal elements. If non-diagonal elements are included, the determinant becomes zero (and hence, $\boldsymbol{S}_{y}^{-1}$ cannot be calculated), since we have assumed the same relative errors (1\%) of measured quantities. The uncertainties of the dust model parameters are not yet precisely known. Thus, we assume the standard deviations to be half of the variation range in Table 1 , and the variancecovariance matrix $S_{e}$ is constructed by considering diagonal elements only (i.e., $\left[\operatorname{diag}\left(S_{e}\right)\right]^{1 / 2}=\Delta x / 2$ ).

The relation between the regularization parameter $(\gamma)$ of dust model parameters and the diagonal elements of AKM is plotted in Fig. 6. The averaging kernel close to 1.0 corresponds to the case that the model parameter is mostly determined by the observed DSR/SSR data while the averaging kernel being close to 0.0 is the case of the model parameter being mainly determined by the a priori data. Since observational parameters have large sensitivity to the four dust model parameters $\left(\tau, r_{\mathrm{eff}}, v_{\mathrm{eff}}\right.$, and $\left.\rho_{A}\right)$, the residuals of observational parameters 

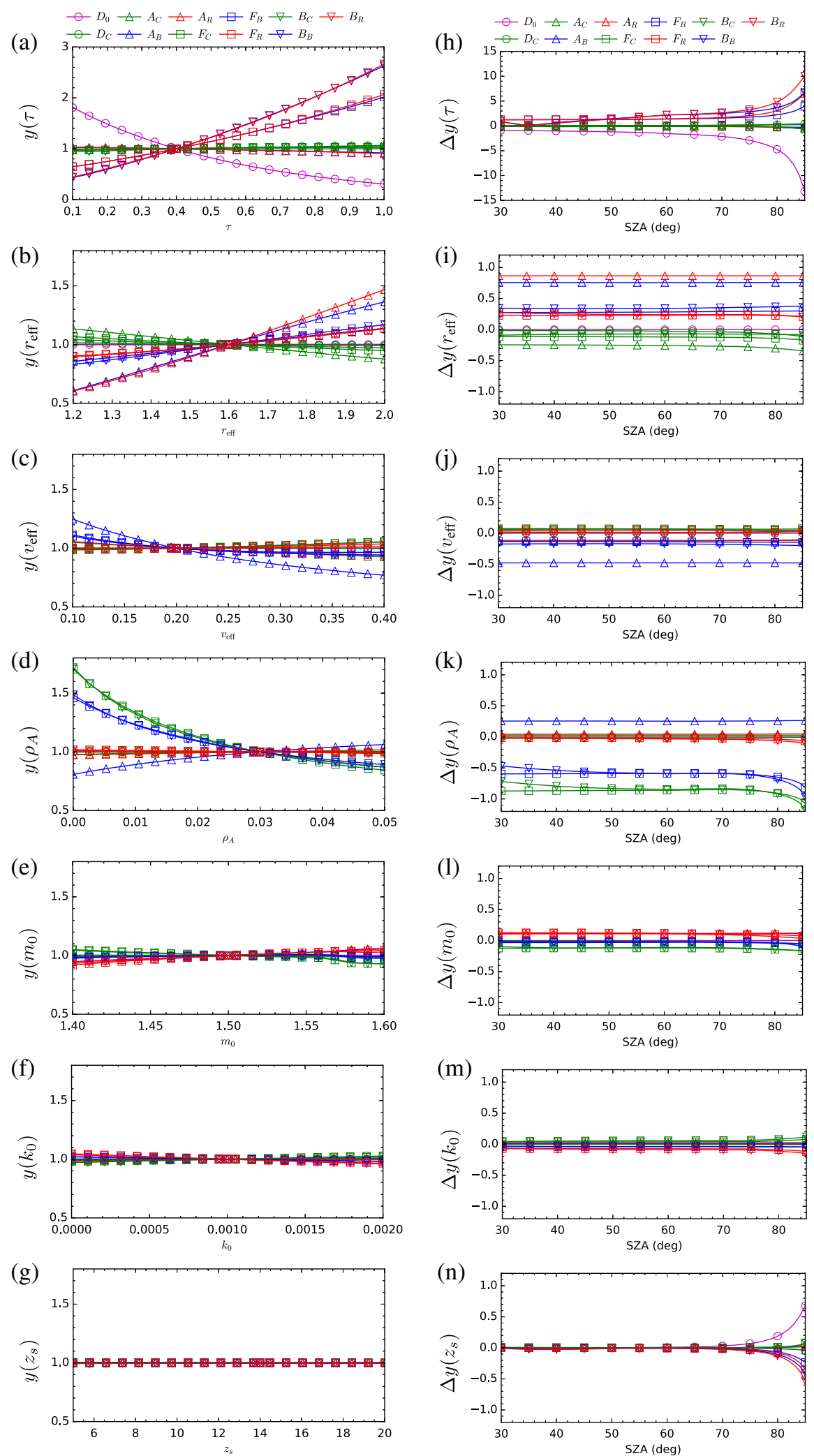

Fig. 5 Sensitivity of observational parameters to dust model parameters. Parameters $y$ and $\Delta y$ represent the normalized observational parameter, and the difference between the maximum and minimum values of $y$ when the dust model parameter is changed from its minimum to maximum value, respectively. See Table 5 for the definitions of $D_{0}, D_{C_{1}}$ Panels $(\mathbf{a})$ - $(\mathbf{g})$ show the relation between $y\left(X_{i}\right)$ and $X_{i}$ for $X_{1}-X_{7}$, respectively, and panels $(\mathbf{h})$ - $(\mathbf{n})$ show that between $\Delta y\left(X_{i}\right)$ and SZA for $X_{1}-X_{7}$, respectively 


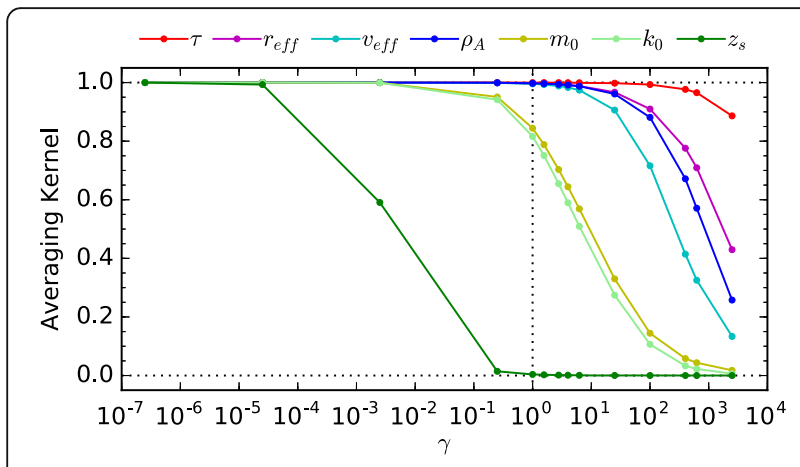

Fig. 6 Relation between regularization parameter $(\gamma)$ of dust model parameters and diagonal elements of AKM. This graph shows an increased importance of a priori parameters for increasing $\gamma$. An SZA of $60^{\circ}$ has been assumed for this calculation

increase when $\gamma$ increases in the range of $\gamma>1$. Although a matrix form of $\gamma$ can potentially be adopted so as to enable the separate adjustment of regularization strength for each dust model parameter, here, we use the same regularization parameter of $\gamma=1$ for all dust model parameters for the sake of simplicity. When $\gamma=1, z_{s}$ is almost confined to its a priori value $(14 \mathrm{~km})$.

\section{Consideration on cases with insufficient data availability}

In the actual lander mission, there might be cases in which DSR/SSR cannot be observed at some specific scattering angles or accurate color ratios cannot be obtained due to reasons such as the limited dynamic range of the sensor, bad observation conditions, difficulty in calibration, etc. In view of such possibilities, here, we estimate propagation errors for the following six cases: case 1. Full utilization of all observational parameters; case 2. DSRs $\left(D_{0}, D_{C}\right)$ are not available; case 3. Aureoles $\left(A_{C}, A_{B}, A_{R}\right)$ are not available; case 4. Forward scattering values $\left(F_{C}, F_{B}, F_{R}\right)$ are not available; case 5 . Backward scattering values $\left(B_{C}, B_{B}, B_{R}\right)$ are not available; and case 6 . Color ratios $\left(D_{C}, A_{C}\right.$, $\left.F_{C}, B_{C}\right)$ are not available.

First, the diagonal elements of AKM for these six cases are shown in Fig. 7 (left scale). In case 1, the averaging kernels of $\tau, r_{\text {eff }}, v_{\text {eff, }}$, and $\rho_{A}$ are almost in unity and those of $m_{0}$ and $k_{0}$ are about 0.8 . Thus, observation information is well reflected in the retrieved values of these dust model parameters. On the other hand, the averaging kernels of $z_{s}$ are much smaller and nearly zero at SZA $>55^{\circ}$, which means that $z_{s}$ is almost confined to its a priori value. In other cases, averaging kernels are smaller as compared with case 1 and dependence on a priori is larger especially in cases 3 and 6 .

Combined propagation errors of the dust model parameters $\left(\boldsymbol{E}_{c}=\left[\operatorname{diag}\left(\boldsymbol{S}_{c}\right)\right]^{1 / 2}\right)$ are shown in Fig. 8. For the evaluation of retrieval errors, errors relative to the a priori values are intuitively more understandable than those relative to the variation range, and hence, here errors are expressed as values relative to both variation ranges $(\Delta X)$ and a priori values $\left(X_{a}\right)$. Errors relative to a priori values are obtained from errors relative to variation range multiplied by $\Delta X / X_{a}$ in Table 1 . The left and right scales of Fig. 8 are normalized so that $\Delta x=1$ and $x_{a}=1$, respectively. In case 1 , the combined propagation errors normalized with $\Delta x$ (normalized with $x_{a}$ ) are as follows; $\tau$ : $0.5-2 \%$ (1$4 \%), r_{\text {eff: }}: 3 \%(2 \%), v_{\text {eff: }}: 4 \%(5 \%)$, and $\rho_{A}: 2-3 \%(4-6 \%)$. Compared with case 1 , the total propagation errors are larger especially in the following cases; $\tau$ : case 2 , $r_{\text {eff: }}$ cases 3 and $6, v_{\text {eff: }}$ case 3 , and $\rho_{A}$ : cases 2,3 , and 6. As for $m_{0}$ and $k_{0}$, the combined propagation errors of both parameters in case 1 are about $20 \%$ of $\Delta x$, which is 3 and $40 \%$ of $x_{a}$ for $m_{0}$ and $k_{0}$, respectively. The errors of $m_{0}$ and $k_{0}$ are larger especially in case 3 (without aureole) and case 6 (without color ratio). The combined propagation error of $z_{\mathrm{s}}$ is close to the a priori error $(\Delta x / 2)$ since $z_{s}$ is almost confined to its a priori value. The percentage of a priori error in the combined propagation error is larger if the error ratio shown in Fig. 8 (right scale) is larger. The above propagation errors have been estimated with a relative measurement error of $1 \%$, and it is expected that the propagation error is proportional to the measurement error if it is sufficiently small. Note, however, that the percentage of a priori error changes if the weight ratio of $\boldsymbol{K}_{x}^{\mathrm{T}} \boldsymbol{S}_{y}^{-1} \boldsymbol{K}_{x}$ and $\mathbf{S}_{a}^{-1}$ changes.

Once a retrieval error occurs in a dust model parameter, it may propagate to the other model parameters. This effect becomes significant if the non-diagonal elements of AKM are not negligible. The non-diagonal elements of AKM in the above six cases are shown in Fig. 9. Since we have assumed that all of the diagonal elements of $S_{a}$ are the same (i.e., $\left[\operatorname{diag}\left(\boldsymbol{S}_{a}\right)\right]^{1 / 2}=\Delta \boldsymbol{x} / 2$ ), AKM $\left(A_{\mathrm{ij}}=\partial x_{r, i} / \partial x_{j}\right)$ is symmetric and we show only elements which satisfy $i>j$ and $A_{i j}>0.02$ at one of the considered SZAs. We can see that $m_{0}$ and $k_{0}\left(x_{r}: k_{0}, x: m_{0}\right)$ are easily influenced by each other (especially in case 6). Also, in case 3 , the correlation becomes larger between $m_{0}$ and size distribution parameters $\left(r_{\text {eff }}\right.$ and $\left.v_{\text {eff }}\right)$.

\section{Non-spherical dust shape}

Previous studies on terrestrial aerosols have shown that the differences in the shapes of coarse mode particles play an important role in the spectra of DSR and SSR, since scattering patterns are dependent on the spherical (hygroscopic) or non-spherical (such as desert dust) shapes of aerosol particles. Dubovik et al. (2006) reported that the light scattering properties of desert dust aerosols in the terrestrial atmosphere can 
$\rightarrow$ Case $1 \rightarrow$-Case $2 \rightarrow$-Case $3-0$-Case $4 \rightarrow$-Case $5 \rightarrow$ Case6
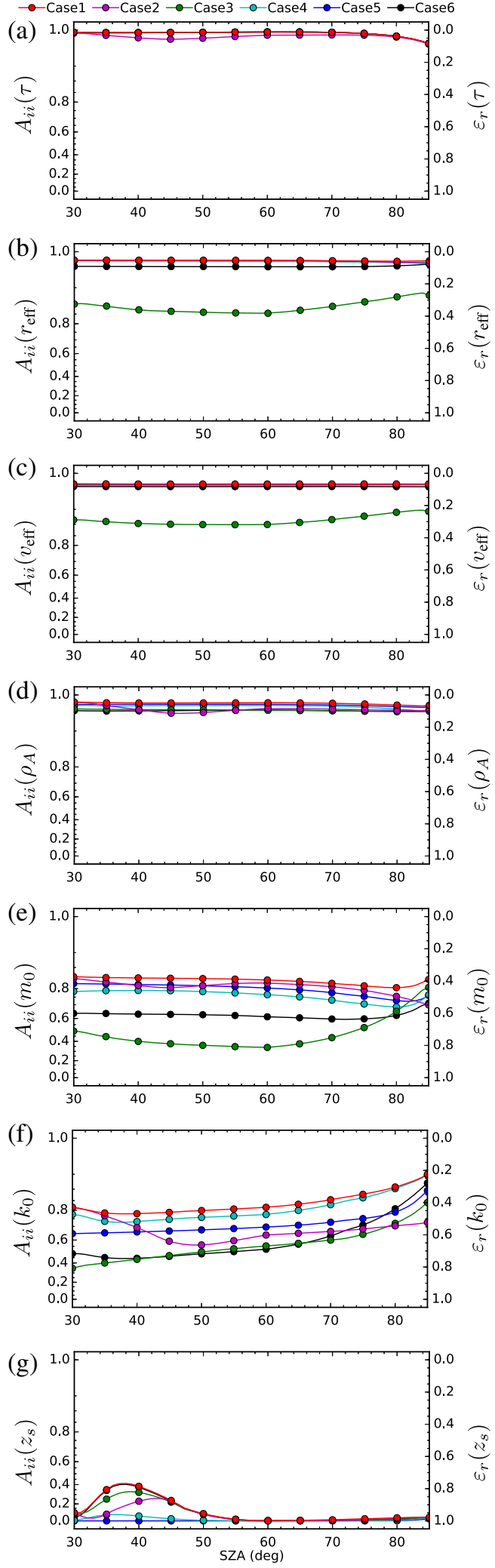

Fig. 7 Diagonal elements of AKM and error ratio of dust model parameters. The left and right scales are for AKM and error ratio, respectively. Case 1, with all observation parameters listed in Table 5; case 2, without DSR; case 3, without aureole; case 4, without forward scattering; case 5 without backward scattering; and case 6, without color ratio. Averaging kernel closer to unity means that information from observations is more significant. Panels (a) - (g) show the relation between $A_{i i} / \varepsilon_{r, i}$ and SZA for $X_{1}-X_{7}$, respectively

be modeled by considering a mixture of spherical and non-spherical aerosol types. For non-spherical particles, their aspect ratio distribution was estimated from a feldspar sample (Dubovik et al. 2006). Following their treatment, we assume in the present analysis that the optical properties of Martian dust can be modeled by adjusting the volume mixing ratio $\left(\rho_{N}\right)$ of non-spherical particles to spherical particles. Variation ranges for all the observational parameters listed in Table 5 are examined by changing the value of $\rho_{N}$ between 0 and 1. The results are plotted in Fig. 10a as functions of SZA. Among the 11 observational parameters, $A_{B}=\operatorname{SSR}\left(\lambda_{B}, \chi_{A}\right) / \operatorname{SSR}\left(\lambda_{B}, \chi_{0}\right)$ exhibits the largest sensitivity to $\rho_{N}\left(\Delta y\left(\rho_{N}\right)=0.15\right)$. Relatively large dependence on SZA is seen for parameters related to backscattering $\left(B_{R}, B_{C}\right.$, and $\left.B_{B}\right)$. Figure $10 \mathrm{~b}$ shows the systematic errors of retrieved dust model parameters when the wrong assumption of $\rho_{N}=0$ (spherical) is adopted to analyze the observational data of dust particles that are totally non-spherical $\left(\rho_{N}=1\right)$. The parameters except $v_{\text {eff }}$ and $k_{0}$ have small systematic errors (less than $15 \%$ ). The parameters $v_{\text {eff }}$ and $k_{0}$ show errors as large as 25 and $80 \%$ of their variation ranges $(\sim 40 \%$ and $160 \%$ of their a priori values), respectively. Thus, it is desirable to take the non-sphericity of dust particles into account in the retrieval of dust model parameters as with our dust model.

\section{Bimodal size distribution}

We have so far assumed a monomodal size distribution based on coarse mode dust particles. From the simultaneous observation in the ultraviolet and infrared ranges by SPICAM on Mars Express, however, Fedorova et al. (2014) reported the existence of fine mode (radius 0.04$0.07 \mu \mathrm{m}$ ) as well as coarse mode (average radius $0.7 \mu \mathrm{m}$ ) particles in the higher altitudes, ranging between 10 and $80 \mathrm{~km}$. Therefore, in this part, we examine the influence of additional fine mode particles in our model calculation. In order to reduce the number of dust model parameters, we assume that the complex RI of the fine mode is the same as that of the coarse mode particles. For the coarse mode, we employ the gamma distribution of Eq. (2) with $r_{\text {eff }}=1.6 \mu \mathrm{m}$ and $v_{\text {eff }}=0.2$ as before. For the fine mode, we follow the model given by Fedorova et al. (2014), namely, a log-normal distribution with effective 

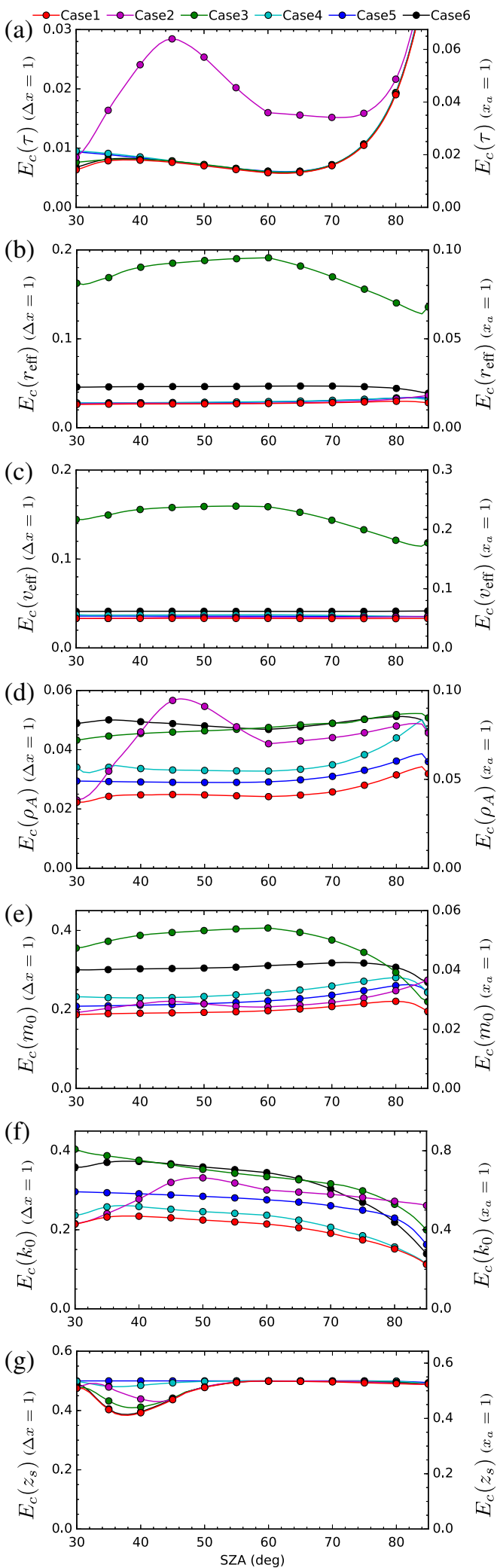

Fig. 8 Combined propagation errors of dust model parameters. The definitions of cases 1-6 are the same as in Fig. 7. The left and right scales are normalized so that $\Delta x=1$ and $x_{a}=1$, respectively, and panels (a) - (g) show the relation between propagation error and SZA for $X_{1}-X_{7}$, respectively radius $r_{2}=0.06 \mu \mathrm{m}$ and effective variance $v_{2}=0.1$. A lognormal distribution is given as

$$
\frac{\mathrm{d} N}{\mathrm{~d} \ln r}=\frac{1}{\sigma \sqrt{2 \pi}} \exp \left[-\frac{\left(\ln r-\ln r_{\text {mod }}\right)^{2}}{2 \sigma^{2}}\right] .
$$

Here, $r_{\text {mod }}$ is the mode radius and $\sigma$ is the standard deviation. The values of mode radius and standard derivation can be calculated from the effective radius and variance as $r_{\text {mod }}=r_{2}\left(v_{2}+1\right)^{-5 / 2}$ and $\sigma=\left[\ln \left(v_{2}+1\right)\right]^{1 / 2}$, respectively. We parameterize the volume mixing ratio of the fine mode $\left(\rho_{F}\right)$ between 0 (the a priori value) and 0.01 .

The sensitivities of dust observation parameters to the volume mixing ratio of fine mode dust $\left(\rho_{F}\right)$ are shown in Fig. 11a. Observational parameters such as $F_{B}, F_{C}, B_{B}$, and $B_{C}$ (i.e., parameters related to SSR in the blue band except aureole) are particularly sensitive to $\rho_{F}$.

Figure 11b shows the systematic errors of retrieved dust model parameters when the wrong assumption of $\rho_{F}=0$ (monomodal) is adopted, while the true value of $\rho_{F}$ is 0.01 (slightly bimodal). Figure $11 \mathrm{~b}$ indicates that the magnitudes of error in $\rho_{A}$ and $k_{0}$ are at most $10 \%$ of their variation range ( $\sim 20 \%$ of their a priori values) even when the volume mixing ratio of fine mode is as large as $1 \%$. Since the presence of fine mode particles in the lower Mars atmosphere has not been reported conclusively, it would be justified to assume the monomodal size distribution as in the present analysis. Nevertheless, to validate such a monomodal assumption, it is desirable to check the fitting result of real data to be obtained in future Mars lander missions.

\section{Sensitivity analysis and error estimation for TCWV measurement}

In a similar way as applied to the dust model parameters, sensitivity analysis for water vapor retrieval is made by changing the value of $c_{w}$ between 0.476 and $4.76 \mathrm{mg} /$ $\mathrm{cm}^{2}$ (corresponding to 100 and $1000 \mathrm{ppm}$, respectively). Figure 12 shows the resulting curves of the variation ranges (sensitivities) of the observational parameters plotted against SZA. The SZA dependencies of the sensitivities of $D_{2}=\operatorname{DSR}\left(\lambda_{W}\right) / \operatorname{DSR}\left(\lambda_{S}\right)$ and $D_{3}=\operatorname{DSR}\left(\lambda_{W}\right) /$ $\operatorname{DSR}_{0}\left(\lambda_{W}\right)$ to $c_{w}$ are very similar. While $D_{3}$ is sensitive only to $c_{w}, D_{2}$ exhibits large sensitivity not only to $c_{w}$ but also to $\tau$. Thus, $D_{3}$ is a better parameter than $D_{2}$ for the $c_{w}$ retrieval, as expected from the better knowledge of the spectral intensity around the absorption band. As for SSR, both $S_{2}=\operatorname{SSR}\left(\lambda_{W}\right) / \operatorname{SSR}\left(\lambda_{S}\right)$ and $S_{3}=\operatorname{SSR}\left(\lambda_{W}\right) /$ $\operatorname{SSR}_{0}\left(\lambda_{W}\right)$ exhibit similar SZA dependence of the sensitivities to $c_{w}$, and the advantage of using $S_{2}$ or $S_{3}$ for the retrieval of $c_{w}$ is that the magnitudes of the sensitivities are approximately three times larger than those of $D_{2}$ and $D_{3}$. A drawback, however, is that they show 


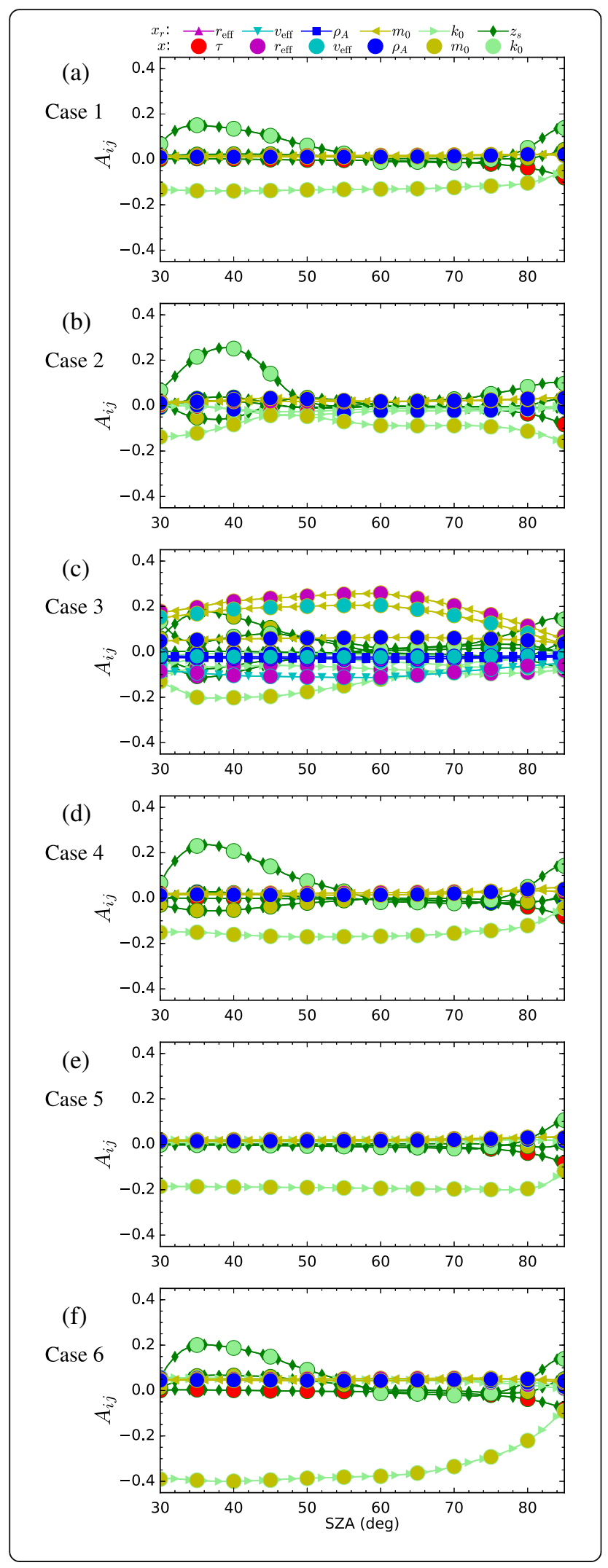

Fig. 9 Non-diagonal elements of AKM $\left(A_{i j}=\partial x_{r, i} / \partial x_{j}\right)$ of dust model parameters. The lines with small symbols indicate the type of retrieved dust parameters $\left(x_{r}\right)$, while the large circles indicate the type of true dust parameters $(x)$. Panels (a) - (f) show the relation between $A_{i j}$ and SZA for cases 1-6, respectively. The definitions of cases 1-6 are the same as in Fig. 7. These graphs are useful for the examination of error propagation from one dust parameter to another (see text)

sensitivities to $\tau$ and $z_{s}$ in addition to $c_{w}$. Especially, the dependence on $z_{s}$ can be problematic, since this parameter cannot be measured accurately through dust observations. This problem is hardly improved even with three wavelengths, since the difference of $\tau$ or $z_{s}$ results in a change of effective optical path length due to multiple scattering, and hence, the change in the amount of water vapor absorption itself. It should be pointed out, however, that we may be able to retrieve the value of $z_{s}$ if both DSR and SSR can be measured simultaneously. Moreover, a better prospect for $z_{s}$ retrieval may possibly be achieved by measuring carbon dioxide $\left(\mathrm{CO}_{2}\right)$ absorption with the MAX-DOAS technique (Irie et al. 2008), since it would be relatively easy to estimate the vertical distribution of $\mathrm{CO}_{2}$, and the molecule has strong absorption bands in the near infrared region (e.g., $1050 \mathrm{~nm}$ ).

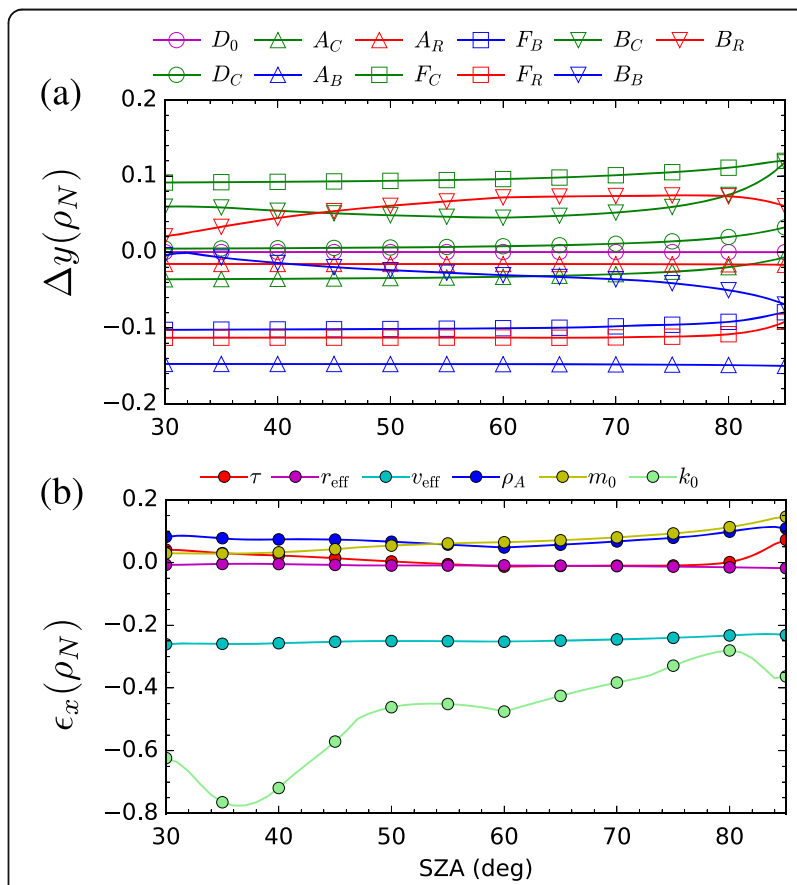

Fig. 10 a Sensitivity of dust observation parameters to the volume mixing ratio of non-spherical dust $\left(\rho_{N}\right)$. Parameter $\Delta y$ represents the difference between the maximum and minimum values of the normalized observational parameters when $\rho_{N}$ is changed from 0 to 1 . b Systematic error due to non-spherical dust shape. Systematic errors of normalized dust model parameters are estimated from differences between observational parameters calculated with true (1) and wrong (0) values of the volume mixing ratio of non-spherical dust $\left(\rho_{N}\right)$ 


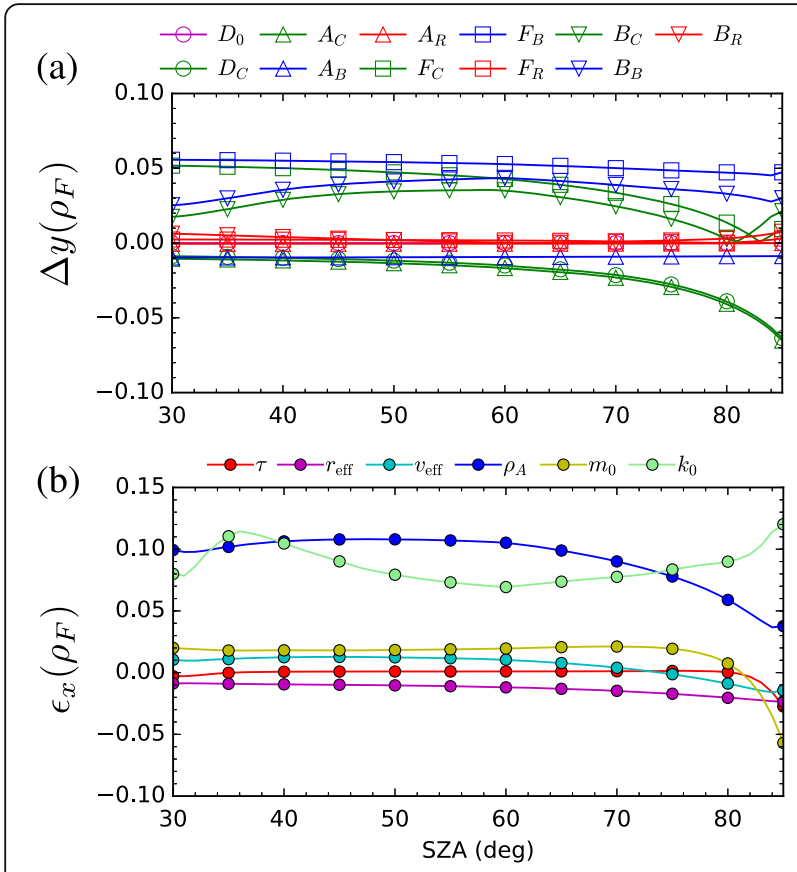

Fig. 11 a Sensitivity of dust observation parameters to the volume mixing ratio of fine mode dust $\left(\rho_{F}\right)$. Parameter $\Delta y$ represents the difference between the maximum and minimum values of the normalized observational parameters when $\rho_{N}$ is changed from 0 to 0.01. b Systematic error due to ignorance of bimodal size distribution. The systematic errors of the normalized dust model parameters are estimated from the differences between the observational parameters calculated with true $(0.01)$ and wrong $(0)$ values of the fine mode dust volume mixing ratio $\left(\rho_{F}\right)$

Here, we estimate the retrieval error of TCWV $\left(c_{w}\right)$ when $c_{w}$ and dust model parameters are retrieved simultaneously. We assume a relative measurement error of $1 \%$, and a regularization parameter $\gamma_{d}=1$ is employed for dust model parameters. Figure 13 shows the relation between the regularization parameter $\left(\gamma_{w}\right)$ of TCWV and the diagonal elements of AKM. Here, SZA is fixed at $80^{\circ}$. When $\gamma_{w}=1$, the diagonal elements of AKM with $D_{2}$ or $D_{3}$ are about 0.4 and the influence of the a priori information is significant. Hence, we take $\gamma_{w}=0.06$, at which the diagonal elements of AKM are larger than 0.9. Weakening the regularization strength results in vulnerability to the random error of measurements, but such influence can be reduced by increasing averaging or exposure time of the camera measurement.

We consider four cases in which one of $D_{2}, D_{3}, S_{2}$, or $S_{3}$ is used for the retrieval of $c_{w}$. The diagonal elements of AKM for the four different cases are shown in Fig. 14 (left scale). The difference between two and three wavelengths turns out to be insignificant. In the cases of DSR $\left(D_{2}, D_{3}\right)$, the averaging kernels are around $0.7-0.9$, while in the cases of SSR $\left(S_{2}, S_{3}\right)$ the averaging kernels are about 0.98 .

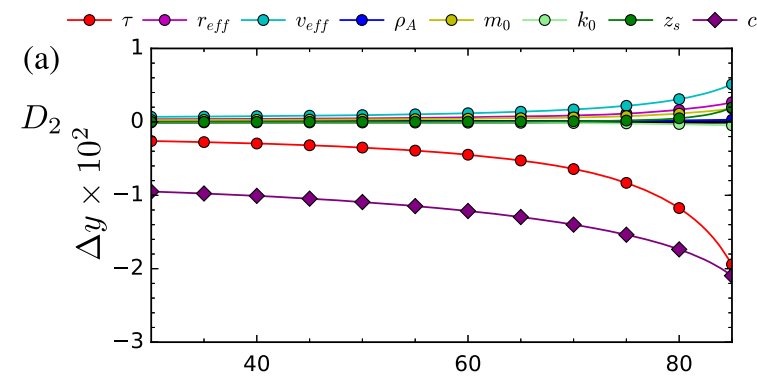

(b)

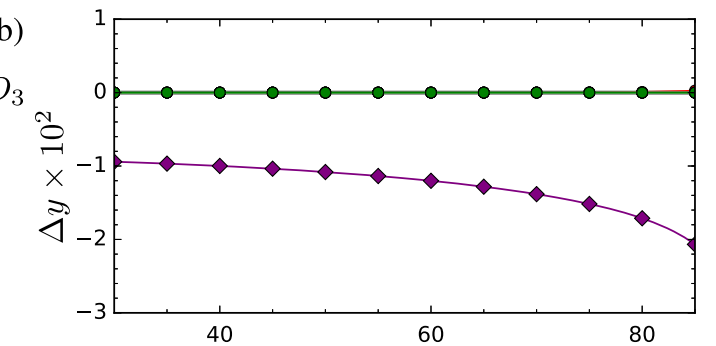

(c)

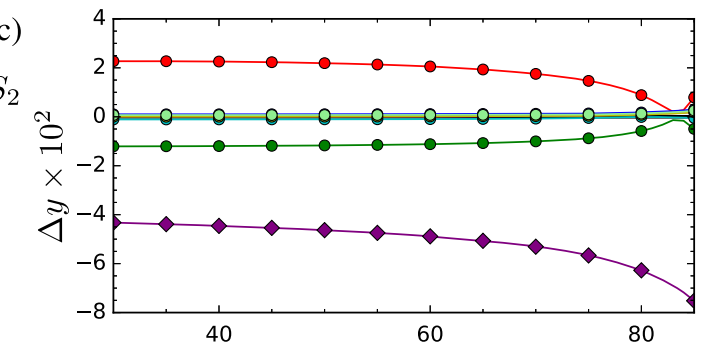

(d)

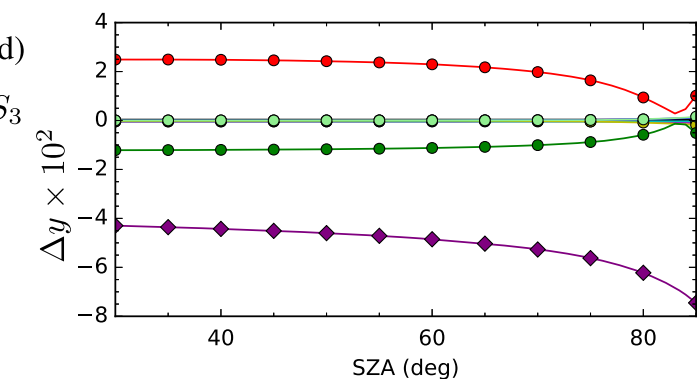

Fig. 12 Sensitivities of water vapor observation parameters to TCW and dust model parameters. Panels (a) - (d) show the relation between $\Delta y\left(C_{w}\right)$ and SZA for $D_{2}, D_{3}, S_{2}$, and $S_{3}$, respectively

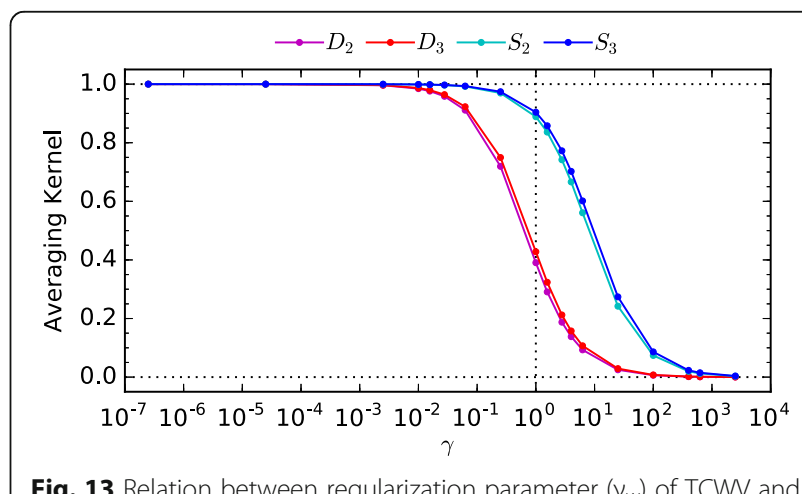
diagonal elements of AKM 

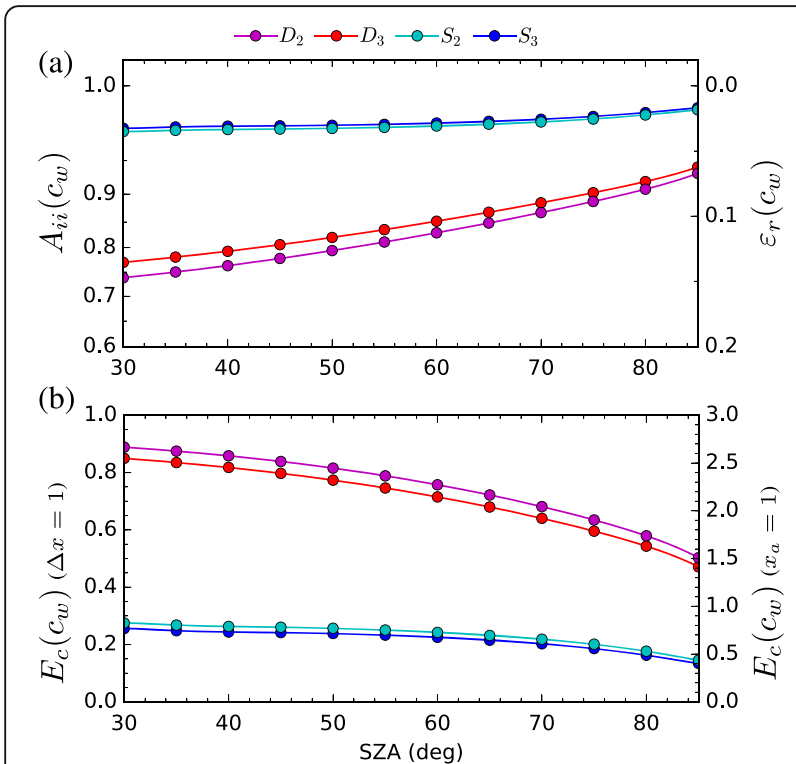

Fig. 14 a Diagonal elements of AKM and error ratio of TCWV. As compared with DSR, SSR results show stronger dependence on observation data of $c_{w}$ rather than a priori data. $\mathbf{b}$ Combined propagation errors of TCWV. The left and right scales are normalized so that $\Delta x=1$ and $x_{a}=1$, respectively

The combined propagation errors are shown in Fig. 14b. They include the contributions from both measurement errors and a priori errors according to the error ratio shown in Fig. 14a (right scale). Again, the difference between two and three wavelengths is insignificant. Looking around $\mathrm{SZA}=80^{\circ}$, the propagation errors normalized by $x_{a}$ are 1.7 and 0.5 when we use DSR and SSR, respectively. This means that if we can suppress the measurement error down to $1 \%$, SSR-based retrieval of $c_{w}$ can achieve a precision of $50 \%$ of its a priori value.

As seen above, it is expected that the combined propagation errors are smaller if we use SSR rather than DSR. In the case of SSR, on the other hand, the amplitudes of non-diagonal elements of AKM are larger (Fig. 15), and the retrieved $c_{w}$ is more affected by the retrieval error of dust model parameters (especially $z_{s}$ ), which is consistent with the results of the present sensitivity analysis (Fig. 12). However, the error of $c_{w}$ due to the error in $z_{s}$ is at most $\sim 15 \%$ of the variation range $(50 \%$ of the a priori value). Also, the influence of the water vapor profile on SSR is expected to be small for any particular value of $c_{w}$. Therefore, it is advantageous to use SSR, and if available, using both SSR and DSR is desirable.

\section{Applicability of the present algorithm}

In order to check the practical applicability of our algorithms, we estimate the measurement noise assuming sensor specifications that can be realized with the current technology. We employ radiative transfer

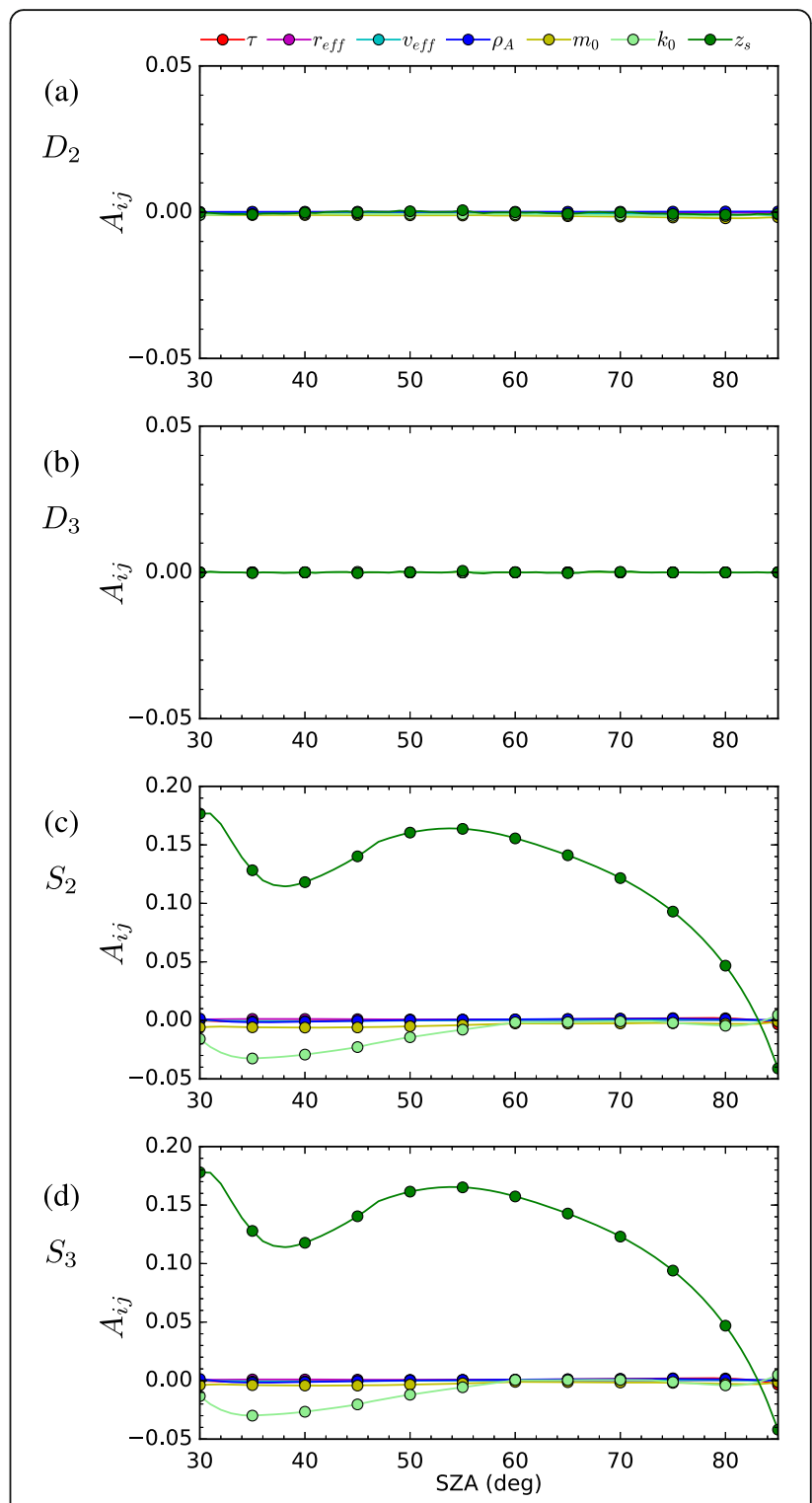

Fig. 15 Non-diagonal elements of AKM of TCWV. Panels (a) - (d) show the relation between $A_{i j}$ and SZA for $D_{2}, D_{3}, S_{2}$, and $S_{3}$, respectively

simulation to estimate the minimum signal strength of SSR. The simulation conditions assumed for minimizing SSR intensity are an SZA of $80^{\circ}$, scattering angle of $120^{\circ}$, and dust optical depth of 0.1. Then, signal-to-noise (S/ N) ratio is estimated from the SSR intensity. Only the shot noise of the sensor has been considered in this calculation, on the assumption that the dark noise and readout noise are negligibly small.

If we assume a focal length of $10 \mathrm{~mm}$, an array with 500 pixels, and a field-of-view (FOV) angle of $30^{\circ}$, the sizes of a sensor element and array width are calculated to be approximately 10 and $5.2 \mathrm{~mm}$, respectively. A twodimensional image sensor that fulfills such specifications is easily available. Even when the signal strength is at its 
minimum and the exposure time is as short as $1 \mathrm{~s}$, it is expected that the random noise is less than $0.5 \%$, and hence, an S/N ratio over 200 can be attained. Actually, the exposure time can be much longer than $1 \mathrm{~s}$, since a temporal resolution of $1 \mathrm{~min}$, for example, is still acceptable. Therefore, the proposed scheme of DSR/SSR observation is practical and achievable by means of hardware existing today.

\section{Conclusions}

We have constructed a Martian dust model in order to retrieve optical/physical properties of Martian dust from DSR/SSR spectra to be measured by a multi-wavelength environmental camera onboard a Mars lander. We have assumed that Martian dust is composed of silicate-like substrate and hematite-like inclusion. The dust shape is assumed to be spheroid with a monomodal gamma size distribution and a fixed aspect ratio distribution estimated from a terrestrial feldspar sample. The spatial distribution of dust is homogeneous horizontally, and its concentration decreases exponentially with increasing altitude. Our Martian dust model is parameterized with seven parameters, namely, real $\left(m_{0}\right)$ and imaginary $\left(k_{0}\right)$ parts of silicate RI, volume mixing ratio of hematite $\left(\rho_{A}\right)$, effective radius $\left(r_{\text {eff }}\right)$ and variance $\left(v_{\text {eff }}\right)$ of size distribution, optical depth $(\tau)$, and scale height $\left(z_{s}\right)$ of extinction coefficient at a wavelength of $550 \mathrm{~nm}$. On the other hand, we consider 11 observational parameters, namely, intensity of DSR at $550 \mathrm{~nm}\left(D_{0}\right)$, color ratio of DSR between blue and red bands $\left(D_{C}\right)$, relative intensities of aureole, forward scattering, and backward scattering with respect to the SSR at the reference scattering angle for the blue and red bands $\left(A_{B}, A_{R}, F_{B}, F_{R}, B_{B}, B_{R}\right)$, and color ratio of SSR $\left(A_{C}, F_{C}, B_{C}\right)$.

From the result of error analysis using simulated data, relative errors (combined propagation error from both measurement and a priori data) of dust model parameters, comparing them to a measurement error of $1 \%$, have been estimated as $\tau: 1-4 \%, r_{\text {eff }}: 2 \%, v_{\text {eff: }}: 5 \%, \rho_{A}: 4-$ $6 \%, m_{0}: 3 \%$, and $k_{0}: 40 \%$ of their a priori values. The value of $z_{s}$ is almost confined to its a priori value, due to the lack of sensitivity in our observation scheme. Increase of retrieval error is observed when some of the observational parameters are omitted from the retrieval procedure. Such observational parameters are $\tau$ : DSR $\left(D_{0}, D_{C}\right), r_{\text {eff: }}$ aureole $\left(A_{C}, A_{B}, A_{R}\right)$ and color ratio $\left(D_{C}\right.$, $\left.A_{C}, F_{C}, B_{C}\right), v_{\text {eff: }}$ aureole, $\rho_{A}$ : DSR, aureole and color ratio, $m_{0}$ and $k_{0}$ : aureole and color ratio. If spherical shape is employed to retrieve the dust model parameters from the observational parameters calculated for nonspherical shape, we expect a systematic error of $v_{\text {eff }}$ as large as $40 \%$ of its a priori value. If a monomodal gamma distribution of coarse particles is employed in finding model parameters from observational ones but the true size distribution is bimodal containing $1 \%$ fine mode particles by volume, we expect a systematic error of $\rho_{A}$ as large as $20 \%$ of its a priori value.

Water vapor has absorption bands inside the sensitive range of a CMOS sensor, and we can measure TCWV $\left(c_{w}\right)$ from absorbed amount in DSR or SSR intensity. We considered four observational parameters of spectral ratio $\left(D_{2}, D_{3}, S_{2}, S_{3}\right)$ calculated with DSR or SSR at two or three wavelengths. Using simulation, it has been confirmed that if we use SSR instead of DSR for the observational parameter, larger sensitivity can be expected, with the relative error of $c_{w}$ against $1 \%$ of measurement error being $50 \%$ of its a priori value.

The measurement noise estimated with currently available sensor specifications is sufficiently small, and thus, we conclude that the proposed scheme of dust retrieval with DSR/SSR observation is practical.

\section{Abbreviations \\ AKM: Averaging Kernel Matrix; CMOS: Complementary metal-oxide semicon- ductor; DSR: Direct solar radiation; FOV: Field of view; LOS: Line of sight; MAX-DOAS: Multi-axis differential optical absorption spectroscopy; RI: Refractive index; SSR: Scattered solar radiation; SZA: Solar zenith angle; TCWV: Total column water vapor; VMR: Volume mixing ratio}

\section{Funding}

This work was supported by the joint research program of CEReS, Chiba university $(2015,2016)$.

\section{Authors' contributions}

$\mathrm{NM}, \mathrm{KN}, \mathrm{GLH}$, and MS proposed the topic, and conceived and designed the study. NM carried out the simulation study. NM and KN wrote the manuscript. HK contributed to editing the manuscript. HS and NO provided ideas for the study. All authors read and approved the final manuscript.

Competing interests

The authors declare that they have no competing interest.

\section{Publisher's Note}

Springer Nature remains neutral with regard to jurisdictional claims in published maps and institutional affiliations.

\section{Author details}

${ }^{1}$ Center for Environmental Remote Sensing, Chiba University, 1-33 Yayoi-cho, Inage-ku, Chiba-shi, Chiba 263-8522, Japan. ${ }^{2}$ Department of Chemistry, Biology, and Environmental Science, Faculty of Science, Nara Women's University, Kita-uoya Nishi-machi, Nara-shi, Nara 630-8506, Japan. ${ }^{3}$ Department of Earth Sciences, Okayama University, 3-1-1 Tsushimanaka, Kita-ku, Okayama-shi, Okayama 700-8530, Japan. ${ }^{4}$ Planetary Exploration Research Center, Chiba Institute of Technology, 2-17-1 Tsudanuma, Narashino-shi, Chiba 275-0016, Japan. ${ }^{5}$ Department of Earth System Science, Faculty of Science, Fukuoka University, 8-19-1 Nanakuma, Jonan-ku, Fukuoka-shi, Fukuoka 814-0180, Japan. Institute of Space and Astronautical Science, Japan Aerospace Exploration Agency, 3-1-1 Yoshinodai, Chuo-ku, Sagamihara-shi, Kanagawa 252-5210, Japan.

Received: 1 October 2016 Accepted: 4 June 2017

Published online: 21 June 2017

\section{References}

Bell JF, Squyres SW, Herkenhoff KE, Maki JN, Arneson HM, Brown D, Collins SA, Dingizian A, Elliot ST, Hagerott EC, Hayes AG, Johnson MJ, Johnson JR, Joseph J, Kinch K, Lemmon MT, Morris RV, Scherr L, Schwochert M, Shepard MK, Smith GH, Sohl-Dickstein JN, Sullivan RJ, Sullivan WT, Wadsworth M 
(2003) Mars Exploration Rover Athena Panoramic Camera (Pancam) investigation. J Geophys Res Planets 108(E12):8063. doi:10.1029/2003JE002070

Bell JF, Squyres SW, Arvidson RE, Arneson HM, Bass D, Calvin W, Farrand WH, Goetz W, Golombek M, Greeley R, Grotzinger J, Guinness E, Hayes AG, Hubbard MYH, Herkenhoff KE, Johnson MJ, Johnson JR, Joseph J, Kinch KM, Lemmon MT, Li R, Madsen MB, Maki JN, Malin M, McCartney E, McLennan S, McSween HY, Ming DW, Morris RV, Dobrea EZN et al (2004a) Pancam multispectral imaging results from the Opportunity Rover at Meridiani Planum. Science 306(5702):1703-1709. doi:10.1126/science.1105245

Bell JF, Squyres SW, Arvidson RE, Arneson HM, Bass D, Blaney D, Cabrol N, Calvin W, Farmer J, Farrand WH, Goetz W, Golombek M, Grant JA, Greeley R, Guinness E, Hayes AG, Hubbard MYH, Herkenhoff KE, Johnson MJ, Johnson JR, Joseph J, Kinch KM, Lemmon MT, Li R, Madsen MB, Maki JN, Malin M, McCartney E, McLennan S, McSween HY et al (2004b) Pancam multispectral imaging results from the Spirit Rover at Gusev Crater. Science 305(5685):800806. doi:10.1126/science.1100175

Berk A, Anderson GP, Acharya PK, Bernstein LS, Muratov L, Lee J, Fox M, AdlerGolden SM, Chetwynd JH Jr, Hoke ML, Lockwood RB, Gardner JA, Cooley TW, Borel CC, Lewis PE, Shettle EP (2006) MODTRAN5: 2006 update. In: Shen SS, Lewis PE (eds) Proceedings of SPIE 6233, Orlando, 17 April 2006.. doi:10.1117/ 12.665077

Dabrowska DD, Muñoz O, Moreno F, Ramos JL, Martínez-Frías J, Wurm G (2015) Scattering matrices of Martian dust analogs at $488 \mathrm{~nm}$ and $647 \mathrm{~nm}$. Icarus 250:83-94. doi:10.1016/j.icarus.2014.11.024

Dlugach ZM, Korablev Ol, Morozhenko AV, Moroz VI, Petrova EV, Rodin AV (2003) Physical properties of dust in the Martian atmosphere: analysis of contradictions and possible ways of their resolution. Sol Syst Res 37(1):1-19. doi:10.1023/A:1022395404115

Doicu A, Trautmann T, Schreler F (2010) Numerical regularization for atmospheric inverse problems. Springer, Heidelberg

Dubovik O, Sinyuk A, Lapyonok T, Holben BN, Mishchenko M, Yang P, Eck TF, Volten H, Muñoz O, Veihelmann B, van der Zande WJ, Leon J-F, Sorokin M, Slutsker I (2006) Application of spheroid models to account for aerosol particle nonsphericity in remote sensing of desert dust. J Geophys Res Atmos 111(D11). doi:10.1029/2005JD006619.

Ehlers K, Chakrabarty R, Moosmüller H (2014) Blue moons and Martian sunsets. Appl Opt 53(9):1808-1819. doi:10.1364/AO.53.001808

Fedorova AA, Korablev OI, Bertaux J-L, Rodin AV, Montmessin F, Belyaev DA, Reberac A (2009) Solar infrared occultation observations by SPICAM experiment on Mars-Express: simultaneous measurements of the vertical distributions of H2O, CO2 and aerosol. Icarus 200(1):96-117. doi:10.1016/j. icarus.2008.11.006

Fedorova AA, Montmessin F, Rodin AV, Korablev OI, Määttänen A, Maltagliati L, Bertaux J-L (2014) Evidence for a bimodal size distribution for the suspended aerosol particles on Mars. Icarus 231:239-260. doi:10.1016/j.icarus.2013.12.015

Flasar FM, Goody RM (1976) Diurnal behaviour of water on mars. Planet Space Sci 24(2):161-181. doi:10.1016/0032-0633(76)90103-3

Gierasch PJ, Goody RM (1972) The effect of dust on the temperature of the Martian atmosphere. J Atmos Sci 29(2):400-402

Haberle RM, McKay CP, Schaeffer J, Cabrol NA, Grin EA, Zent AP, Quinn R (2001) On the possibility of liquid water on present-day Mars. J Geophys Res Planets 106(E10):23317-23326. doi:10.1029/2000JE001360

Hamilton VE, Christensen PR (2005) Evidence for extensive, olivine-rich bedrock on Mars. Geology 33(6):433-436. doi:10.1130/G21258.1

Hansen JE, Travis LD (1974) Light scattering in planetary atmospheres. Space SCi Rev 16(4):527-610. doi:10.1007/BF00168069

Hinson DP, Wilson RJ (2004) Temperature inversions, thermal tides, and water ice clouds in the Martian tropics. J Geophys Res Planets 109(E1). doi:10.1029/ 2003JE002129. E01002.

Hoekzema NM, Garcia-Comas M, Stenzel OJ, Grieger B, Markiewicz WJ, Gwinner K Keller HU (2010) Optical depth and its scale-height in Valles Marineris from HRSC stereo images. Earth Planet Sci Lett 294(3-4):534-540. doi:10.1016/j. epsl.2010.02.009

Irie H, Kanaya Y, Akimoto H, Iwabuchi H, Shimizu A, Aoki K (2008) First retrieval of tropospheric aerosol profiles using MAX-DOAS and comparison with lidar and sky radiometer measurements. Atmos Chem Phys 8(2):341-350

Isaacs RG, Wang W-C, Worsham RD, Goldenberg S (1987) Multiple scattering lowtran and fascode models. Appl Opt 26(7):1272-1281. doi:10.1364/AO.26.001272

Komguem L, Whiteway JA, Dickinson C, Daly M, Lemmon MT (2013) Phoenix LIDAR measurements of Mars atmospheric dust. Icarus 223(2):649-653. doi: 10.1016/j.icarus.2013.01.020
Lemmon MT, Wolff MJ, Smith MD, Clancy RT, Banfield D, Landis GA, Ghosh A, Smith PH, Spanovich N, Whitney B, Whelley P, Greeley R, Thompson S, Bell JF, Squyres SW (2004) Atmospheric imaging results from the Mars exploration rovers: Spirit and Opportunity. Science 306(5702):1753-1756. doi: 10.1126/science. 1104474

Lemmon MT, Smith PH, Shinohara C, Tanner R, Woida P, Shaw A, Hughes J, Reynolds R, Woida R, Penegor J, Oquest C, Hviid SF, Madsen MB, Olsen M, Leer K, Drube L, Morris RV, Britt DT (2008) The Phoenix Surface Stereo Imager (SSI) Investigation. Lunar and planetary science conference, League City, pp 10-14, March 2008

Levoni C, Cervino M, Guzzi R, Torricella F (1997) Atmospheric aerosol optical properties: a database of radiative characteristics of different components and classes. Appl Opt 36(30):8031-8041

Malin MC, Caplinger MA, Edgett KS, Ghaemi FT, Ravine MA, Schaffner JA, Baker JM, Bardis JD, Dibiase DR, Maki JN, Willson RG, Bell JF, Dietrich WE, Edwards L, Hallet B, Herkenhoff KE, Heydari E, Kah LC, Lemmon MT, Minitti ME, Olson TS, Parker TJ, Rowland SK, Schieber J, Sullivan RJ, Sumner DY, Thomas PC, Yingst RA (2010) The Mars Science Laboratory (MSL) Mast-mounted Cameras (Mastcams) flight instruments. Lunar and planetary science conference, Woodlands, pp 1-5, March 2010

Manago N, Kuze H (2010) Determination of tropospheric aerosol characteristics by spectral measurements of solar radiation using a compact, stand-alone spectroradiometer. Appl Opt 49(8):1446-1458. doi:10.1364/AO.49.001446

Manago N, Miyazawa S, Bannu KH (2011) Seasonal variation of tropospheric aerosol properties by direct and scattered solar radiation spectroscopy. J Quant Spectrosc Radiat Transf 112(2):285-291. doi:10.1016/j.jqsrt.2010.06.015

Markiewicz WJ, Sablotny RM, Keller HU, Thomas N, Titov D, Smith PH (1999) Optical properties of the Martian aerosols as derived from Imager for Mars Pathfinder midday sky brightness data. J Geophys Res Planets 104(E4):90099017. doi:10.1029/1998JE900033

Millour E, Forget F, Spiga A, Colaitis A, Navarro T, Madeleine J-B, Chauffray J-Y, Montabone L, Lopez-Valverde MA, Gonzalez-Galindo F, Lefevre F, Montmessin F, Lewis SR, Read PL, Desjean M-C, Huot J-P (2012) Mars Climate Database version 5. European planetary science congress, Madrid, pp 23-28, September 2012

Mishchenko MI, Travis LD (1998) Capabilities and limitations of a current FORTRAN implementation of the T-matrix method for randomly oriented, rotationally symmetric scatterers. J Quant Spectrosc Radiat Transf 60(3):309324. doi:10.1016/S0022-4073(98)00008-9

Moore CA, Moores JE, Lemmon MT, Rafkin SCR, Francis R, Pla-García J, Haberle RM, Zorzano M-P, Martín-Torres FJ, Burton JR (2016) A full Martian year of line-of-sight extinction within Gale Crater, Mars as acquired by the MSL Navcam through sol 900. Icarus 264:102-108. doi:10.1016/j.icarus.2015.09.001

Moores JE, Lemmon MT, Smith PH, Komguem L, Whiteway JA (2010) Atmospheric dynamics at the Phoenix landing site as seen by the Surface Stereo Imager. J Geophys Res Planets 115(E1). doi:10.1029/2009JE003409. E00E08

Moriyama S (1975) Effects of dust on radiation transfer in the Martian atmosphere, (2). J Meteor Soc Japan 53(3):214-221

Patterson WR, Huck FO, Wall SD, Wolf MR (1977) Calibration and performance of the Viking Lander cameras. J Geophys Res 82(28):4391-4400. doi:10.1029/ JS082i028p04391

Pike WT, Staufer U, Hecht MH, Goetz W, Parrat D, Sykulska-Lawrence H, Vijendran S, Madsen MB (2011) Quantification of the dry history of the Martian soil inferred from in situ microscopy. Geophys Res Lett 38(24). doi:10.1029/ 2011 GL049896

Pollack JB, Colburn D, Kahn R, Hunter J, Van Camp W, Carlston CE, Wolf MR (1977) Properties of aerosols in the Martian atmosphere, as inferred from Viking Lander imaging data. J Geophys Res 82(28):4479-4496. doi:10.1029/ JS082i028p04479

Pollack JB, Colburn DS, Flasar FM, Kahn R, Carlston CE, Pidek D (1979) Properties and effects of dust particles suspended in the Martian atmosphere. J Geophys Res Solid Earth 84(B6):2929-2945. doi:10.1029/JB084iB06p02929

Pollack JB, Ockert-Bell ME, Shepard MK (1995) Viking Lander image analysis of Martian atmospheric dust. J Geophys Res Planets 100(E3):5235-5250. doi:10. 1029/94JE02640

Querry MR (1985) Optical constants., Technical Report AD-A158-623, DTIC Document

Rodgers CD (2000) Inverse methods for atmospheric sounding: theory and practice vol 2. World scientific, Singapore

Savijärvi H (2014) A toy climate model for Mars. Icarus 242:105-111. doi:10.1016/j. icarus.2014.07.029 
Smith MD (2008) Spacecraft observations of the Martian atmosphere. Annu Rev Earth Planet Sci 36(1):191-219. doi:10.1146/annurev.earth.36.031207.124334 Smith MD (2009) THEMIS observations of Mars aerosol optical depth from 2002-2008. Icarus 202(2):444-452. doi:10.1016/j.icarus.2009.03.027

Smith PH, Lemmon M (1999) Opacity of the Martian atmosphere measured by the imager for Mars Pathfinder. J Geophys Res Planets 104(E4):8975-8985. doi:10.1029/1998JE900017

Smith PH, Tomasko MG, Britt D, Crowe DG, Reid R, Keller HU, Thomas N, Gliem F, Rueffer P, Sullivan R, Greeley R, Knudsen JM, Madsen MB, Gunnlaugsson HP, Hviid SF, Goetz W, Soderblom LA, Gaddis L, Kirk R (1997) The imager for Mars Pathfinder experiment. J Geophys Res Planets 102(E2):4003-4025. doi:10. 1029/96JE03568

Smith PH, Tamppari LK, Arvidson RE, Bass D, Blaney D, Boynton WW, Carswell A, Catling DC, Clark BC, Duck T, DeJong E, Fisher D, Goetz W, Gunnlaugsson HP, Hecht MH, Hipkin V, Hoffman J, Hviid SF, Keller HU, Kounaves SP, Lange CF, Lemmon MT, Madsen MB, Markiewicz WJ, Marshall J, McKay CP, Mellon MT, Ming DW, Morris RV, Pike WT, Renno N, Staufer U, Stoker C, Taylor P, Whiteway JA, Zent AP (2009) H2O at the Phoenix landing site. Science 325(5936):58-61. doi:10.1126/science.1172339

Stamnes K, Tsay S-C, Wiscombe W, Jayaweera K (1988) Numerically stable algorithm for discrete-ordinate-method radiative transfer in multiple scattering and emitting layered media. Appl Opt 27(12):2502-2509. doi:10. 1364/AO.27.002502

Thomas N, Markiewicz WJ, Sablotny RM, Wuttke MW, Keller HU, Johnson JR, Reid RJ, Smith PH (1999) The color of the Martian sky and its influence on the illumination of the Martian surface. J Geophys Res Planets 104(E4):8795-8808. doi:10.1029/98JE02556

Titov DV, Markiewicz WJ, Thomas N, Keller HU, Sablotny RM, Tomasko MG, Lemmon MT, Smith PH (1999) Measurements of the atmospheric water vapor on Mars by the imager for Mars Pathfinder. J Geophys Res Planets 104(E4):9019-9026. doi:10.1029/1998JE900046

Tomasko MG, Doose LR, Lemmon M, Smith PH, Wegryn E (1999) Properties of dust in the Martian atmosphere from the imager on Mars Pathfinder. J Geophys Res Planets 104(E4):8987-9007. doi:10.1029/1998JE900016

Whiteway JA, Komguem L, Dickinson C, Cook C, Illnicki M, Seabrook J, Popovici V, Duck TJ, Davy R, Taylor PA, Pathak J, Fisher D, Carswell Al, Daly M, Hipkin V, Zent AP, Hecht MH, Wood SE, Tamppari LK, Renno N, Moores JE, Lemmon MT, Daerden F, Smith PH (2009) Mars water-ice clouds and precipitation. Science 325(5936):68-70. doi:10.1126/science.1172344

Wolff MJ, Smith MD, Clancy RT, Arvidson R, Kahre M, Seelos F, Murchie S, Savijärvi $H$ (2009) Wavelength dependence of dust aerosol single scattering albedo as observed by the Compact Reconnaissance Imaging Spectrometer. J Geophys Res Planets 114(E2). doi:10.1029/2009JE003350. E00D04.

Yang P, Liou KN (1996) Geometric-optics-integral-equation method for light scattering by nonspherical ice crystals. Appl Opt 35(33):6568-6584. doi:10. 1364/AO.35.006568

\section{Submit your manuscript to a SpringerOpen ${ }^{\circ}$ journal and benefit from:}

- Convenient online submission

- Rigorous peer review

Open access: articles freely available online

- High visibility within the field

Retaining the copyright to your article 